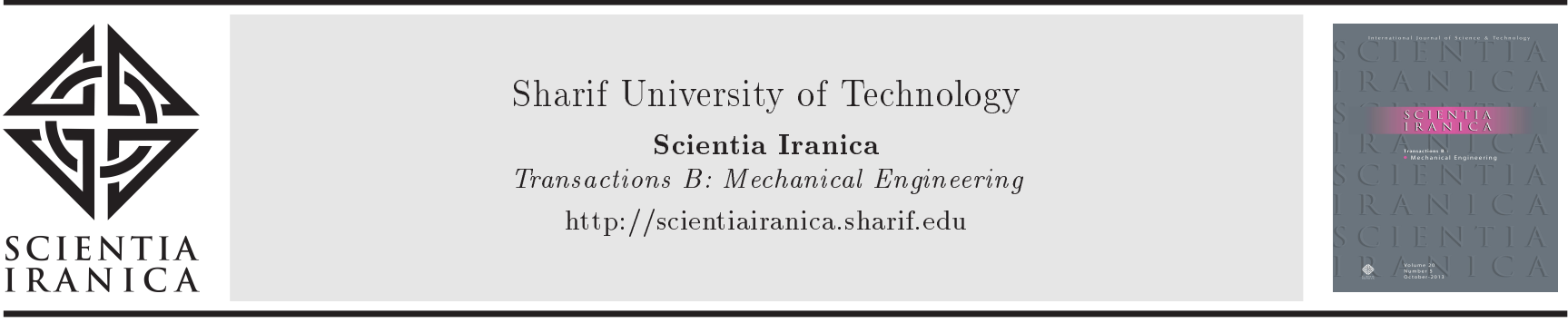

\title{
Numerical study of the influence of suspended equipment on ride comfort in high-speed railway vehicles
}

\section{Dumitriu}

Department of Railway Vehicles, University Politehnica of Bucharest, Romania.

Received 2 May 2018; accepted 23 February 2019

\author{
KEYWORDS \\ Railway vehicle; \\ Flexible car body; \\ Suspended equipment; \\ Vertical bending \\ vibration; \\ Frequency response \\ function; \\ Ride comfort.
}

\begin{abstract}
To study how the suspended equipment affects the car body flexible vibrations in a high-speed railway vehicle and the ride comfort, a rigid flexible general model of such vehicles is required. The numerical simulations of this study relied on three distinct models derived from the general model of the vehicle, namely a reference model with no equipment, a simplified model with one piece of equipment mounted at the car body centre, and a model with four pieces of equipment mounted in various positions along the car body. This paper is intended to fill the gap in the literature, which does not feature any study to highlight the change in the comfort, exclusively due to the equipment. Neither is there any mentioning of the contrast between the results for ride comfort obtained by the simplified model and by the models with more pieces of equipment. The characteristics of the car body flexible vibration with suspended equipment were assessed by comparing the frequency response functions between the no-equipment and one-piece-of-equipment models. The influence of the suspended equipment on the ride comfort was established by comparing the ride comfort indices calculated by one- and four-pieces-of-equipment models with the same index for the no-equipment model.
\end{abstract}

(C) 2020 Sharif University of Technology. All rights reserved.

\section{Introduction}

One of the basic criteria involved in designing highspeed railway vehicles is the reduction in the vehicle weight, particularly the weight of car body, which is the main component of the total vehicle mass. A lighter weight of the vehicle significantly contributes to a higher speed, lower energy consumption, reduction in the ground vibration, and construction-cost saving $[1,2]$.

The weight lightening design of car body implies

\footnotetext{
*. Tel.: 0040744339950

E-mail address: madalinadumitriu@yahoo.com
}

using light materials and altering mechanical structures [3], which often leads to lower car body structural stiffness and, therefore, a decrease in eigenfrequencies. The lighter the vehicle car body, the higher its flexibility. High flexibility will in turn facilitate easy excitation of the car body structural vibrations, which have a negative effect upon the ride comfort. Also, structural vibration leads to car body fatigue, which affects the dynamic performance and service life of the vehicle [4].

The car body structural vibration is rather complex, with global and local mode shapes ranging from car body bending to torsion to the roof and floor, side, and walls vibrations [5]. Nevertheless, the highest influence on the ride comfort comes from the first car body eigenmode of vertical bending the symmetrical bending whose frequency can fall into the range of 6 
to $11 \mathrm{~Hz}$; at this level, human body shows a deeper sensitivity to the vertical vibrations.

The topic of suppressing the car body flexible vibration in the railway vehicles has become a priority for the academic research studies. In recent years, the literature has accommodated more articles on identifying the possibility to reduce the car body vertical vibrations of the high-speed Electric Multiple Units (EMUs). For the lightweight design of the vehicle systems, the layout of the doors and air conditioning installation holes, car body stiffness, and modal frequency should be scaled down. This, in turn, will deteriorate flexible vibration of the car body and affect the ride comfort [6].

Many functional pieces of equipment, such as traction transformer, traction converter, braking unit, cooling unit, air compressor, and waste collection unit, are directly suspended under the car body underframe. Such equipment can weigh from several tens of kilograms to tones and can include their own sources of vibration, namely, the cooling fan and the mechanical switch. Hence, the design of EMU has a significant influence on the car body vertical bending frequency. Depending on the suspension system as well as the equipment mass and its mounting position, the first frequency corresponding to the flexible vibration mode of the car body equipment coupled system can decrease and reach the interval in which human body is more sensitive.

In general, the equipment is elastically suspended using rubber springs in order to avoid noise transmission and to lower the level of car body vibrations so that ride comfort is not significantly affected. However, the identification of the best solution for equipment suspension is still at the core of numerous studies. Many of them focus on the parameters of equipment suspension, i.e. equipment eigenfrequency and the frequency of the first car body vertical bending mode, in correlation with the equipment mass and its mounting position [2,3,7-11]. Basically, the results confirm that the frequency of suspended equipment should be sufficiently low and the equipment should have the largest possible mass and be mounted closest to the car body centre, in order to have a significant reduction in the car body flexible vibration. In addition, there are studies suggesting new methods of designing the equipment suspension [3,12] or new solutions for suspension requiring the use of high-damping elastic supports [13].

According to different design concepts, there are two conventional methods to reduce the EMU car body flexible vibrations, namely vibration isolation and using Dynamic Vibration Absorber (DVA), to which the active reduction in vibrations can be added. However, the latter is not applicable due to its high costs, difficulty to maintain, and limited space of the equipment cabin [12]. The isolation system of vibrations is placed between the equipment and the car body underframe, where the force or the displacement transmission capability between equipment and car body can be reduced. Shi et al. [14] took into account single-stage and two-stage vibration isolation systems in order to study the vibration transmission characteristics of a flexible car body and its suspended equipment. The elastically suspended equipment of the car body can be assumed as a DVA that helps in controlling the amplitude of the car body flexible vibrations. The DVA theory was implemented by Huang et al. [2], Ye et al. [6], and Shi et al. [7] to restrain flexible vibration of the car body in EMU. Based on DVA theory, Shi et al. [7,15] calculated the optimal frequencies of various suspended pieces of equipment. Sun et al. [12] suggest methods for the underframe equipment of a high-speed railway vehicle based on the DVA and vibration isolation theories.

To study the influence of the suspended equipment on the car body flexible vibrations and on the ride comfort, a rigid-flexible coupled model is often used. The model comprises the car body that is modelled via a Euler-Bernoulli beam, a single suspended piece of equipment mounted at the car body centre, and rigid bodies for two bogies and four wheelsets. In this model, only the vertical vibration modes (i.e. bounce, pitch, and flexible bending) influencing the vertical ride comfort are included $[2,7,9,14,16]$. A more complex representation of the car body would use $3 \mathrm{D}$ rigidflexible coupled models built in compliance with the Multi-Body System (MBS) theory and the Finite Element Method (FEM) $[3,6,7,8,12,17]$. In reality, more suspended pieces of equipment are mounted under the EMU underframe, as discussed above. There are a few studies that consider such equipment and they use $3 \mathrm{D}$ rigid-flexible coupled models in line with the MBS theory and the FEM. For instance, Sun et al. [3] offered a 3D model with FE software Hypermesh,in which an electro-pneumatic brake unit, charger, inverter, and battery system were included. Shi et al. [7,18] set up a 3D rigid-flexible coupled vehicle system dynamics model for a passenger coach of EMU by ANSYS and SIMPACK. In this model, six pieces of equipment were mounted on the underframe, namely traction transformer, traction converter, braking unit, power inverter, waste discharge unit, and effluent tank.

There has been no observation made regarding the findings with the simplified model comprising one piece of equipment in comparison with the results for a vehicle with more pieces of equipment. It is worthwhile mentioning that there are no studies on highlighting the ride comfort change exclusively due to the equipment. These observations are the starting point for the study herein.

The paper aims to conduct a numerical study of the impact of suspended equipment on the car body behaviour regarding flexible vibrations. The 
impact is evaluated through frequency response functions calculated in three reference points of the car body at the centre and above the two bogies. Ride comfort is also investigated at the mentioned three reference points. To this end, a general coupled rigidflexible model is considered, which includes a body with parameters dedicated to the car body, six rigid bodies for the bogies and wheelsets, and more rigid bodies for the suspended equipment. To achieve the numerical simulations, three distinct models are derived from the general model of the vehicle, namely a reference model with no equipment, a simplified model with one piece of equipment mounted at the car body centre, and a model with four pieces of equipment installed in different positions along the car body. The DVA theory underlies the calculation of the optimum stiffness, damping of the equipment suspension, and the best frequency. In particular, the objective of this study is twofold. On the one hand, it intends to compare the results of the simplified model with those of the four-pieces-of-equipment model and, on the other hand, it tries to examine the change in the ride comfort exclusively due to the suspended equipment. The latter is done via a comparison of the model with one piece of equipment and the four-pieces-of-equipment model with the results for the no-equipment model.

\section{Model of the vehicle}

To study the influence of the suspended equipment on flexible vibrations of the car body and on the ride comfort, a four-axle, two-stage suspension vehicle is considered, travelling at a constant velocity $V$ on a track, deemed as perfectly rigid, with vertical irregularities. The irregularities of the track are described against each axle via the function $\eta_{j}, j=1 \cdots 4$. The vehicle is represented by a rigid-flexible coupled model (Figure 1), used on a regular basis in such studies thanks to the fact that it displays a good agreement between numerical simulations and field tests [2].

The model features a body with parameters devoted to the car body and several rigid bodies for the bogies, axles, and the suspended equipment. Both the two stages of suspension and the suspension system of the equipment are modelled via Kelvin-Voigt type systems. The parameters for the vehicle model are listed in Table 1.

The car body is represented by a free-free equivalent beam, with constant section and uniformly distributed mass, of Euler-Bernoulli type. The beam parameters are defined in terms of the car body. $L_{c}$ is beam length, $\rho_{c}=m_{c} / L_{c}$ beam mass per length unit with $m_{c}$ representing the car body mass, $\mu$ structural damping coefficient, and $E I$ bending modulus with $E$ being the longitudinal modulus of elasticity and $I$ the area moment of inertia for the transversal section of the beam.

The car body rigid vibration modes, namely bounce $z_{c}$ and pitch $\theta_{c}$, and the first car body bending eigenmode in a vertical plan, namely symmetrical bending, will be taken into account.

The general form of the car body equation of motion is:

$$
\begin{aligned}
E I \frac{\partial^{4} w_{c}(x, t)}{\partial x^{4}} & +\mu I \frac{\partial^{5} w_{c}(x, t)}{\partial x^{4} \partial t}+\rho_{c} \frac{\partial^{2} w_{c}(x, t)}{\partial t^{2}}= \\
& \sum_{i=1}^{2} F_{c i} \delta\left(x-l_{i}\right)+\sum_{k=1}^{n} F_{e k} \delta\left(x-l_{e k}\right),(1)
\end{aligned}
$$

where $\delta($.$) is Dirac delta function; distance l_{i}(i=1,2)$

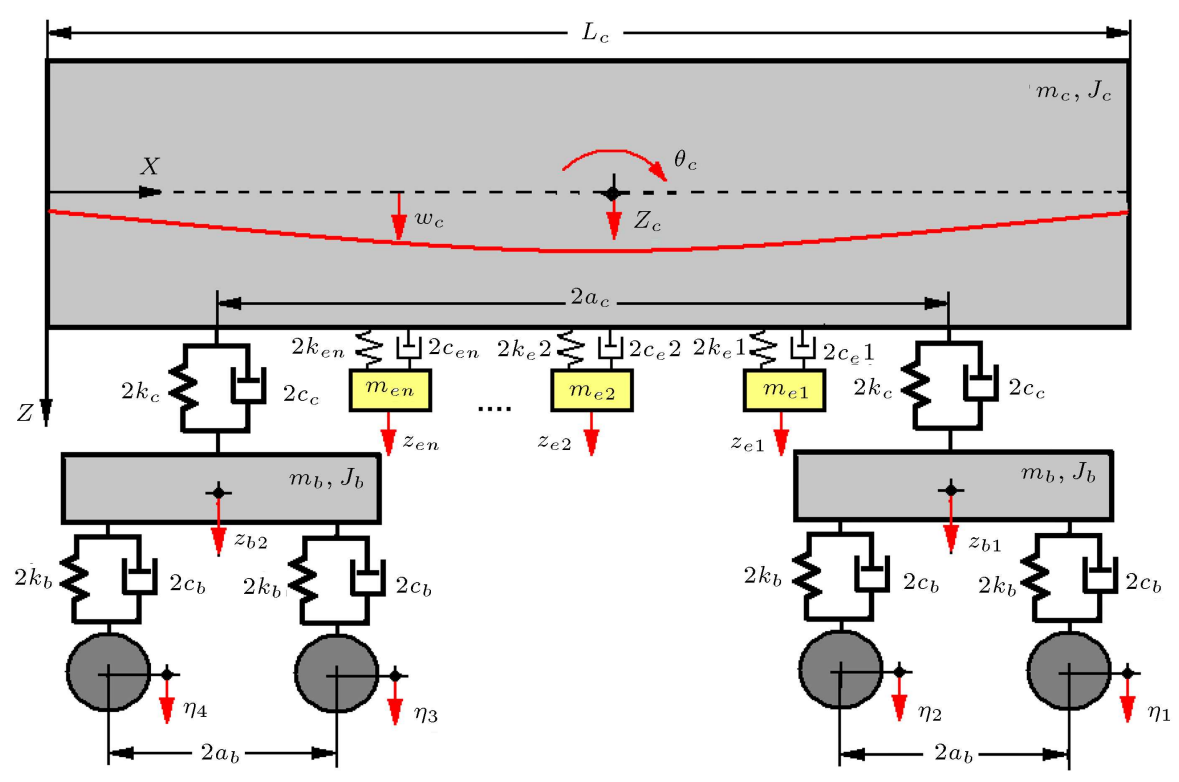

Figure 1. Mechanical model of the vehicle. 
Table 1. Model parameters of the vehicle.

\begin{tabular}{ll}
\hline Symbol & \multicolumn{1}{c}{ Definition } \\
\hline$m_{c}$ & Car body mass \\
$m_{b}$ & Bogie suspended mass \\
$m_{e 1 \cdots n}$ & Equipment mass \\
$J_{c}$ & Car body inertia moment \\
$J_{b}$ & Bogie inertia moment \\
$L_{c}$ & Car body length \\
$2 a_{c}$ & Car body wheelbase \\
$2 c_{c}$ & Secondary suspension damping (per bogie) \\
$2 k_{c}$ & Secondary suspension stiffness (per bogie) \\
$2 c_{b}$ & Primary suspension damping (per axle) \\
$2 k_{b}$ & Primary suspension stiffness (per axle) \\
$22_{c e 1 \cdots n}$ & Suspension damping in the pieces of equipment \\
$2 k_{e 1 \cdots n}$ & Suspension stiffness in the pieces of equipment \\
$2 a_{b}$ & Bogie wheelbase \\
\hline
\end{tabular}

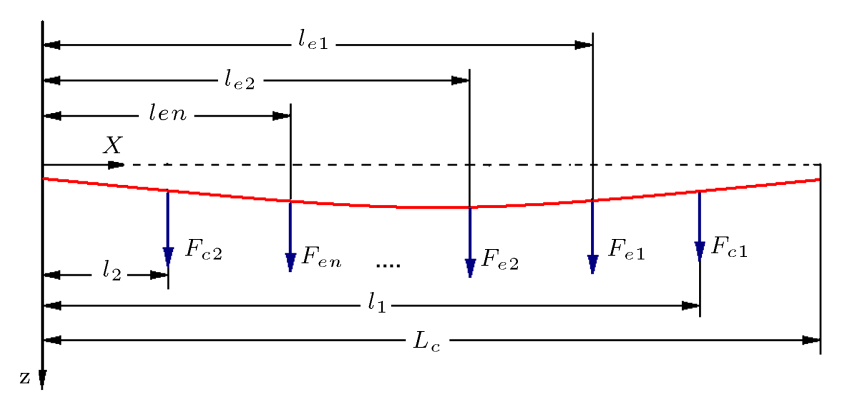

Figure 2. Forces acting upon the car body.

fixes the positions of the supporting points of the car body on the secondary suspension and distance $l_{e k}(k=$ $1 \ldots n)$ fixes the positions of the supporting points of the equipment on the vehicle car body; and $F_{c i}$ stands for the forces derived from the secondary suspension corresponding to bogie $i$ and $F_{e k}$ represents the forces coming from the suspension of equipment (Figure 2).

$$
\begin{aligned}
& F_{c i}=-2 c_{c}\left(\frac{\partial w_{c}\left(l_{i}, t\right)}{\partial t}-\dot{z}_{b i}\right)-2 k_{c}\left(w_{c}\left(l_{i}, t\right)-z_{b i}\right), \\
& F_{e k}=-2 c_{e k}\left[\frac{\partial w_{c}\left(l_{e k}, t\right)}{\partial t}-\dot{z}_{e}\right]-2 k_{e k}\left[w_{c}\left(l_{e k}, t\right)-z_{e k}\right] .
\end{aligned}
$$

The car body vertical movement $w_{c}(x, t)$ comes from the superposition of the two rigid vibration modes, namely bounce and pitch, with the first bending mode:

$$
w_{c}(x, t)=z_{c}(t)+\left(x-\frac{L_{c}}{2}\right) \theta_{c}(t)+X_{c}(x) T_{c}(t)
$$

where $T_{c}(t)$ is the time coordinate of the first bending eigenmode in a vertical plan and $X_{c}(x)$ stands for its eigenfunction .

$$
\begin{aligned}
X_{c}(x)= & \sin \beta x+\sinh \beta x-\frac{\sin \beta L_{c}-\sinh \beta L_{c}}{\cos \beta L_{c}-\cosh \beta L_{c}} \\
& (\cos \beta x+\cosh \beta x),
\end{aligned}
$$

with:

$$
\beta=\sqrt[4]{\omega_{c}^{2} \rho_{c} /(E I)}
$$

and,

$$
\cos \beta L_{c} \cosh \beta L_{c}-1=0,
$$

where $\omega_{c}$ is the natural angular frequency of the car body bending.

When applying the modal analysis method and considering the orthogonality property of the eigenfunction in the car body vertical bending, Eq. (1) turns into three two-order differential equations with ordinary derivatives, describing the movements of bounce, pitch, and bending in the car body:

$$
\begin{aligned}
& m_{c} \ddot{z}_{c}=\sum_{i=1}^{2} F_{c i}+\sum_{k=1}^{n} F_{e k}, \\
& J_{c} \ddot{\theta}_{c}=\sum_{i=1}^{2} F_{c i}\left(l_{i}-\frac{L_{c}}{2}\right)+\sum_{k=1}^{n} F_{e k}\left(l_{e k}-\frac{L_{c}}{2}\right),
\end{aligned}
$$

$$
\begin{aligned}
m_{m c} \ddot{T}_{c}+c_{m c} \dot{T}_{c}+k_{m c} T_{2} \\
=\sum_{i=1}^{2} F_{c i} X_{c}\left(l_{i}\right)+\sum_{k=1}^{n} F_{e k} X_{c}\left(l_{e k}\right),
\end{aligned}
$$

where $k_{m c}, c_{m c}$, and $m_{m c}$ are stiffness, damping, and the car body modal mass given in the following equations:

$$
\begin{aligned}
& k_{m c}=E I \int_{0}^{L}\left(\frac{d^{2} X_{c}}{d x^{2}}\right)^{2} d x, \\
& c_{m c}=\mu I \int_{0}^{L}\left(\frac{d^{2} X_{c}}{d x^{2}}\right)^{2} d x \\
& m_{m c}=\rho_{c} \int_{0}^{L} X_{c}^{2} d x .
\end{aligned}
$$

For each bogie, a single mode of vibration is considered, namely bounce $z_{b i}$ with $i=1,2$. The pitch movement of the bogie is neglected since it is not transmitted to the vehicle car body in this model. 
The equations for the bounce movements of the bogies are:

$$
\begin{aligned}
& m_{b} \ddot{z}_{b 1}=\sum_{j=1}^{2} F_{b j}-F_{c 1}, \\
& m_{b} \ddot{z}_{b 2}=\sum_{j=3}^{4} F_{b j}-F_{c 2},
\end{aligned}
$$

where $F_{b j}$ stands for the forces coming from the primary suspension corresponding to axle $j$ as follows:

$$
F_{b 1,2}=-2 c_{b}\left(\dot{z}_{b 1}-\dot{\eta}_{1,2}\right)-2 k_{b}\left(z_{b 1}-\eta_{1,2}\right),
$$

for $j=1,2$,

$$
F_{b 3,4}=-2 c_{b}\left(\dot{z}_{b 2}-\dot{\eta}_{3,4}\right)-2 k_{b}\left(z_{b 2}-\eta_{13,4}\right),
$$

for $j=3,4$.

The suspended equipment has bounce movements that are described in the following equation:

$$
m_{e k} \ddot{z}_{e k}=-\sum_{k=1}^{n} F_{e k} .
$$

The system comprising Eqs. (8)-(10), (12), (13), and (16) can be written as matrices of the following form:

$$
\mathbf{M} \ddot{\mathbf{p}}+\mathbf{C} \dot{\mathbf{p}}+\mathbf{K} \mathbf{p}=\mathbf{P} \dot{\eta}+\mathbf{R} \eta,
$$

where $\mathbf{M}, \mathbf{C}$, and $\mathbf{K}$ are the inertia, damping, and stiffness matrices, respectively, and $\mathbf{P}$ and $\mathbf{R}$ are the track displacement and velocity input matrices. The motions of each body can be numerically solved using compiled MATLAB codes.

\section{Numerical study}

\subsection{The parameters of the numerical model}

This section deals with the results of the numerical study regarding the influence of the suspended equipment on the car body flexible vibrations, hence using frequency response functions, and on the ride comfort, evaluated by the comfort index.

Three distinct models of the vehicle derived from the general model in the previous section are recognized, namely a reference model with no equipment, a simplified model with one piece of equipment, and a model with four pieces of equipment.

This study intends to compare the results from the simplified model with those from the model with four pieces of equipment, on the one hand, and to examine the change in ride comfort due to the suspended equipment, on the other hand. The latter becomes possible by comparison of the model with one/four piece(s) of equipment with the model with no equipment.
Table 2. Parameters of the numerical model.

$$
\begin{array}{ll}
M_{c}=26000 \mathrm{~kg} & 2 k_{c}=1.2 \mathrm{MN} / \mathrm{m} \\
M_{b}=2050 \mathrm{~kg} & 2 c_{c}=29.97 \mathrm{kNs} / \mathrm{m} \\
J_{c}=1600.10^{3} \mathrm{~kg} \cdot \mathrm{m}^{2} & 4 k_{b}=4.4 \mathrm{MN} / \mathrm{m} \\
J_{b}=830 \mathrm{~kg} \cdot \mathrm{m}^{2} & 4 c_{b}=41.78 \mathrm{kNs} / \mathrm{m} \\
E I=4.2554 .10^{9} \mathrm{Nm}^{2} & m_{m c}=26936 \mathrm{~kg} \\
L_{c}=24.2 \mathrm{~m} & k_{m c}=155.69 \mathrm{MN} / \mathrm{m} \\
2 a_{c}=17.375 \mathrm{~m} ; 2 a_{b}=2.5 \mathrm{~m} & c_{m c}=61.437 \mathrm{kNm} / \mathrm{s} \\
\hline
\end{array}
$$

The reference parameters of the numerical model are given in Table 2 for a motor vehicle of EMU in highspeed railway transport of China [7]. The frequency of vertical bending of the car body with no equipment is $f_{v b}=12.1 \mathrm{~Hz}$, while the frequencies of the car body bounce and pitch are $f_{b c}=1.25 \mathrm{~Hz}$ and $f_{p c}=1.5 \mathrm{~Hz}$, respectively. The frequency of the bogie bounce is $f_{b b}=$ $8.36 \mathrm{~Hz}$.

Six pieces of equipment are suspended from the car body underframe mounted at different distances from the car body end. The heaviest piece weighs $3960 \mathrm{~kg}$ and the lightest $145 \mathrm{~kg}$ (see Table 3 ). To make the numerical study simpler, four out of the six pieces of equipment are considered, which have been selected based on the criterion $m_{e k} / m_{c} \geq 0.02$ (for $k=1 \ldots 4$ ), as seen in Table 3 .

For the model with one piece of equipment, the choice will be the equipment with the largest mass $\left(m_{e 1}=m_{e}=3960 \mathrm{~kg}\right)$, mounted at the centre of the car body $\left(l_{e 1}=l_{e}=L_{c} / 2\right)$, according to the usual models in the literature review $[2,7,9,14,16]$.

Since each one of the four pieces of equipment acts like a DVA, the optimal stiffness and damping in equipment suspension can be established as functions of the optimal tuning ratio $\left(\tau_{e k, o p t}\right)$ and optimal damping $\left(\zeta_{e k, o p t}\right)$, based on Eq. $(2)$, for $k=1 \ldots 4$ :

$$
\begin{aligned}
\tau_{e k, o p t} & =\frac{1}{1+u_{k} X_{c}^{2}\left(l_{e k}\right)}, \\
\zeta_{e k, o p t} & =\sqrt{\frac{3 u_{k} X_{c}^{2}\left(l_{e k}\right)}{8+8 u_{k} X_{c}^{2}\left(l_{e k}\right)}} .
\end{aligned}
$$

Consequently, the optimal stiffness and damping in the equipment suspension can be expressed as follows:

$$
\begin{aligned}
2 k_{e k, \mathrm{opt}} & =m_{e k}\left(2 \pi f_{v b} \tau_{e k, \mathrm{opt}}\right)^{2}, \\
2 c_{e k, \mathrm{opt}} & =\zeta_{e k, \mathrm{opt}}\left(2 \sqrt{2 k_{e k, \mathrm{opt}} m_{e k}}\right) .
\end{aligned}
$$

Similarly, the optimal frequency of the pieces of equipment can be calculated by the relation:

$$
f_{e k, \mathrm{opt}}=f_{v b} \tau_{e k, \mathrm{opt}} .
$$


Table 3. Mass and mounting position of the equipment.

\begin{tabular}{lccc}
\hline \multicolumn{1}{c}{ Equipment } & $\begin{array}{c}\text { Equipment mass } \\
\boldsymbol{m}_{\boldsymbol{e} \boldsymbol{k}}(\mathbf{k g})\end{array}$ & $\begin{array}{c}\text { Mounting position } \\
\boldsymbol{l}_{\boldsymbol{e} \boldsymbol{k}}(\mathbf{m})\end{array}$ & $\begin{array}{c}\text { Mass ratio } \\
\boldsymbol{u}_{\boldsymbol{k}}=\boldsymbol{m}_{\boldsymbol{e}} / \boldsymbol{m}_{\boldsymbol{c}}\end{array}$ \\
\hline Traction transformer & 3960 & 12.8 & 0.1523 \\
Traction converter & 1675 & 7.2 & 0.0644 \\
Braking unit & 400 & 9.9 & 0.0153 \\
Power inverter & 540 & 15.3 & 0.0207 \\
Waste discharge unit & 145 & 23.2 & 0.0055 \\
Effluent tank & 720 & 0.75 & 0.0277 \\
\hline
\end{tabular}

Table 4. Optimal stiffness and damping of the suspension system for the equipment.

\begin{tabular}{lccc}
\hline Equipment mass & $\begin{array}{c}\text { Optimal tuning ratio } \\
\boldsymbol{\tau}_{\boldsymbol{e}, \text { op } \boldsymbol{t}}\end{array}$ & $\begin{array}{c}\text { Optimal damping } \\
\boldsymbol{\zeta}_{\boldsymbol{e}, \boldsymbol{o p} \boldsymbol{t}}\end{array}$ & $\begin{array}{c}\text { Optimal frequency } \\
\boldsymbol{f}_{\boldsymbol{e}, \boldsymbol{o p} \boldsymbol{t}}(\mathbf{H z})\end{array}$ \\
\hline$m_{e 1}=540 \mathrm{~kg}$ & 0.9824 & 0.0813 & 11.88 \\
$m_{e 2}=3960 \mathrm{~kg}$ & 0.8147 & 0.2636 & 9.85 \\
$m_{e 3}=1675 \mathrm{~kg}$ & 0.9817 & 0.0828 & 11.87 \\
$m_{e 4}=720 \mathrm{~kg}$ & 0.9224 & 0.1705 & 11.16 \\
\hline
\end{tabular}

The results from the above equations are included in Table 4. The optimal damping is noticed to have a value too high for the rubber elements that are normally used in the suspension systems of equipment, while the damping ratio should not exceed 0.075 . Otherwise, they get easily heated and hence, they will age and creep quickly [2]. This study will look at the reference value of $\zeta_{e k}=\zeta_{e}=0.025$.

\subsection{Numerical study of the influence of the suspended equipment on the car body flexible vibrations}

3.2.1. Frequency response functions

The study of the influence of the suspended equipment on the car body flexible vibrations will have to deal with the frequency response functions of the vehicle car body. To calculate these functions, the track vertical irregularities against each axle are considered in a harmonic shape with the wavelength $\Lambda$ and amplitude $\eta_{0}$.

$$
\eta_{j}(t)=\eta_{0} \cos \omega t
$$

where $\omega=2 \pi V / \Lambda$ represents the track excitationinduced pulsation. The vehicle response is assumed to be harmonic with the same frequency as the one induced by track excitation.

The response function of the car body displacement at a random point $x$ on the car body longitudinal axis is in the form of:

$$
\begin{aligned}
\bar{H}_{c}(x, \omega)= & \bar{H}_{z_{c}}(\omega)+\left(\frac{L_{c}}{2}-x\right) \bar{H}_{\theta_{c}}(\omega) \\
& +X_{c}(x) \bar{H}_{T_{c}}(\omega)
\end{aligned}
$$

where $\bar{H}_{z_{c}}(\omega), \bar{H}_{\theta_{c}}(\omega)$, and $\bar{H}_{T_{c}}(\omega)$ are the response functions corresponding to the rigid vibration modes, namely bounce $z_{c}$, pitch $\theta_{c}$, and car body vertical bending $T_{c}$.

The response function of car-body acceleration underlies the response function of displacement:

$$
\bar{H}_{a c}(x, \omega)=\omega^{2} \bar{H}_{c}(x, \omega) .
$$

Eq. (25) is customized for three reference points of the car body. A reference point is at the centre of the car body and the other two are placed above the bogies, against the bearing points of the car body on the secondary suspension.

At the car body centre, the acceleration response function is:

$$
\begin{aligned}
\bar{H}_{a c m}(\omega) & =\omega^{2} \bar{H}_{c}\left(\frac{L_{c}}{2}, \omega\right) \\
& =\omega^{2}\left[\bar{H}_{z c}(\omega)+X_{c}\left(\frac{L_{c}}{2}\right) \bar{H}_{T_{c}}(\omega)\right],
\end{aligned}
$$

and above the two bogies, it is:

$$
\begin{aligned}
\bar{H}_{a c b i}(\omega) & =\omega^{2} \bar{H}_{c}\left(l_{i}, \omega\right) \\
& =\omega^{2}\left[\bar{H}_{z_{c}}(\omega) \pm a_{c} \bar{H}_{\theta_{c}}(\omega)+X_{c}\left(l_{i}\right) \bar{H}_{T_{c}}(\omega)\right],
\end{aligned}
$$

for $i=2$

3.2.2. Results of numerical simulations

The first part of this section will review the main characteristics of the car body vibration behaviour due to the existence of the suspended pieces of equipment. To this end, the response functions of car body acceleration for the model with one piece of equipment will 
be calculated and the results will be compared with those for the model with no equipment. It should be mentioned that the eigenfrequency of the equipment for the model with no equipment is $f_{e}$ and the damping ratio of the suspension system is $\zeta_{e}$. Based on the car body acceleration response functions, the differences between the results for the simplified model with one piece of equipment and the findings for the model with four pieces of equipment will also be investigated.

Figure 3 shows the acceleration response functions of the car body at its centre and above the bogies for $\zeta_{e}=0.025$ and various values of eigenfrequency $f_{e}$, including the optimal frequency $f_{e, o p t}$. The car body response above the bogies is considered symmetrical, because the track irregularities defined in Eq. (23) compel in-phase displacement of the four axles of the vehicle and therefore, the car body pitch is not excited. Both diagrams show the peak of resonance frequency in the car body bounce movement at $1.25 \mathrm{~Hz}$. The resonance frequency in the car body vertical bending is at $12.1 \mathrm{~Hz}$ for the model with no equipment, but it changes with the presence of suspended equipment and the way it is fixed on the car body (rigid or elastic). When the equipment is rigidly fixed, the resonance frequency of car body bending lowers to $11 \mathrm{~Hz}$. For the elastically fixed equipment, two peaks emerge corresponding to the resonance frequencies of the equipped car body system; the first one is at a smaller frequency than the resonance frequency of bending in the car body with no equipment and the other one at a higher frequency. The two frequencies will be hereinafter called 'low frequency' and 'high frequency.' It should be mentioned that 'low' frequency is relevant also from the ride comfort perspective, since it can go under $10 \mathrm{~Hz}$. As an example, for $f_{e, o p t}$, the response function of the car body acceleration has a peak at the low frequency of $9.21 \mathrm{~Hz}$, which corresponds to the in-phase vibration in the car body and equipment, and another peak at the high frequency of $14 \mathrm{~Hz}$, which is for the anti-phase vibration in the car body and equipment. The response function in the car body acceleration increases with the eigenfunction of the equipment at low frequency, while goes down with $f_{e}$.

It is deducible that the level of car body vibrations changes at the bending resonance frequencies once the suspended equipment is introduced in the model of the vehicle. Rigid fixation of the equipment leads to decrease in the acceleration response function at the car body centre and above the bogies. For an elastic suspension of equipment, the level of vibrations at the car body centre shows a noticeable reduction at both resonance frequencies, irrespective of the eigenfrequency of the equipment. Nevertheless, in case of bending frequency in the car body with no equipment, the response function at low frequency will rise above the bogies for $f_{e} \geq 9.85 \mathrm{~Hz}$. These results are rather relative, since the level of vibrations above the bogies declines with the rise in the damping degree of the equipment, as shown below.

Considering the optimal value of the eigenfrequency of the equipment $\left(f_{e, o p t}\right)$, the response functions of car body acceleration were calculated for various values of the damping ratio $\zeta_{e}$, as seen in Figure 4. The level of car body vibrations at the resonance frequencies of the car body equipment coupled system decreases with increase in $\zeta_{e}$. In the results for the model with no equipment, the level of vibrations is noticeably lower than that at the car body centre in all the cases being studied, but above the bogies, it is $\zeta_{e} \geq 0.05$. Both at the car body centre and above the bogies, the most efficient reduction in the bending vibrations is recorded for the optimal value of the damping ratio, which is 0.2636 in this study.

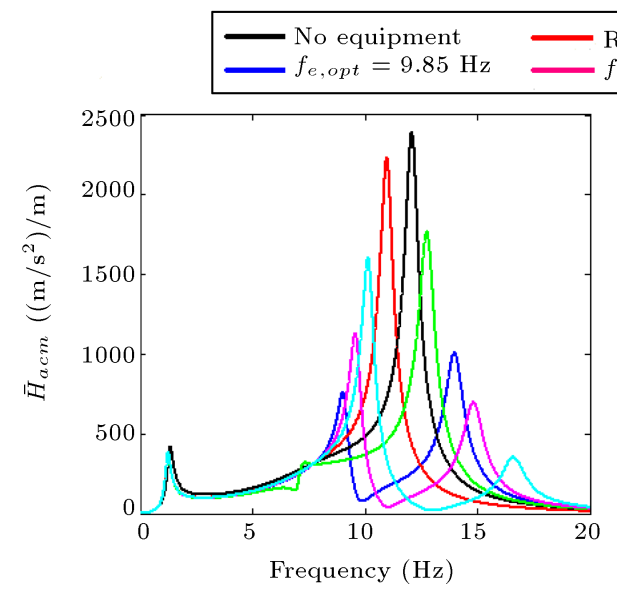

(a)

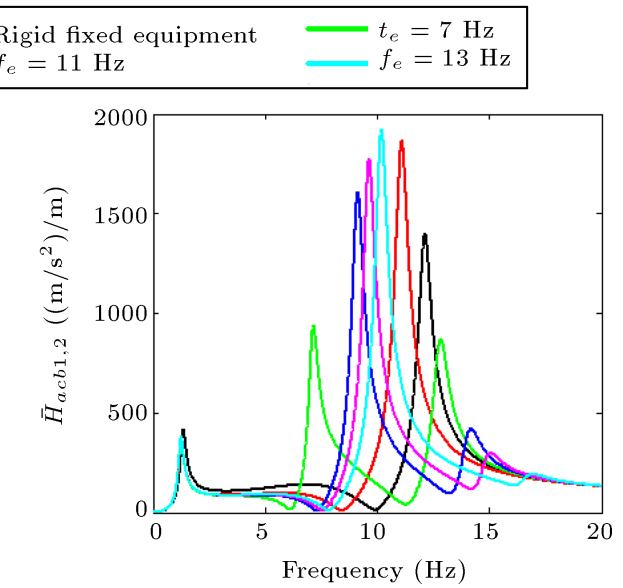

(b)

Figure 3. Response function of car body acceleration; influence of the eigenfrequency of the equipment: (a) At the car body centre and (b) above the bogies. 


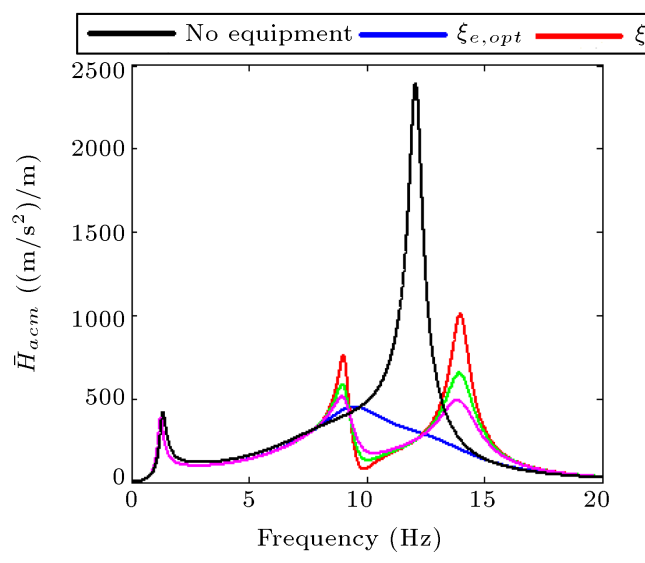

(a)

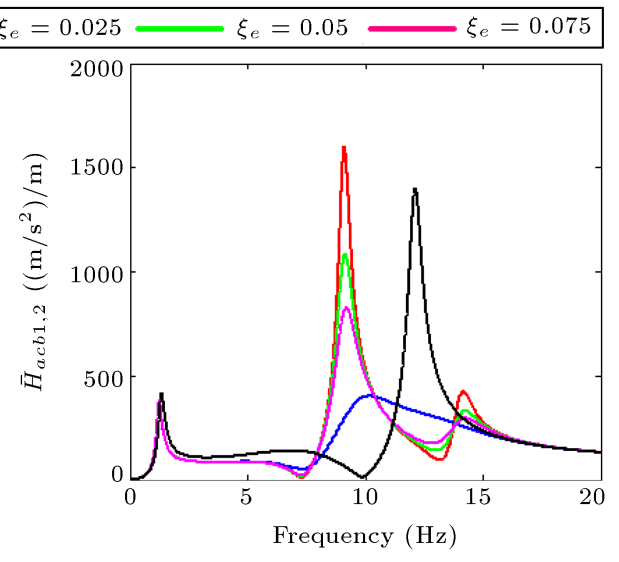

(b)

Figure 4. Response function of the car body acceleration; influence of damping ratio of the equipment: (a) At the car body centre and (b) above the bogies.

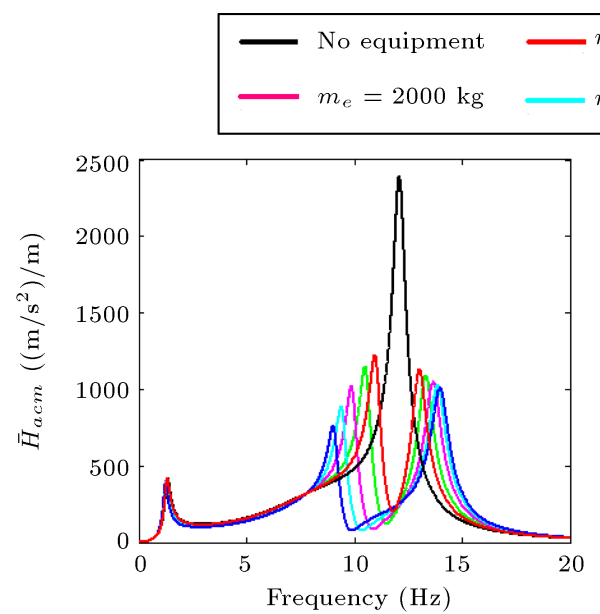

(a)

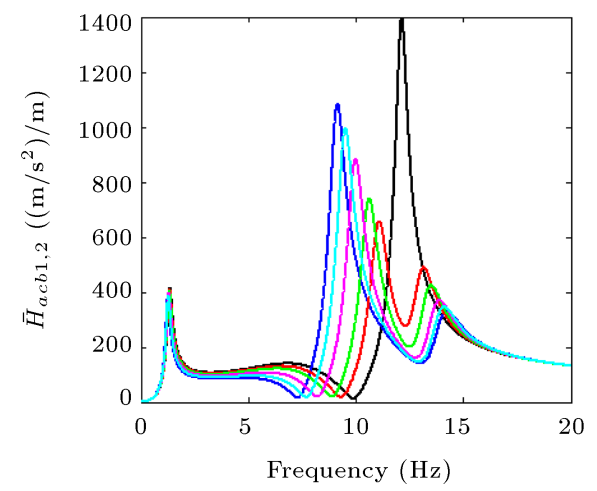

(c)

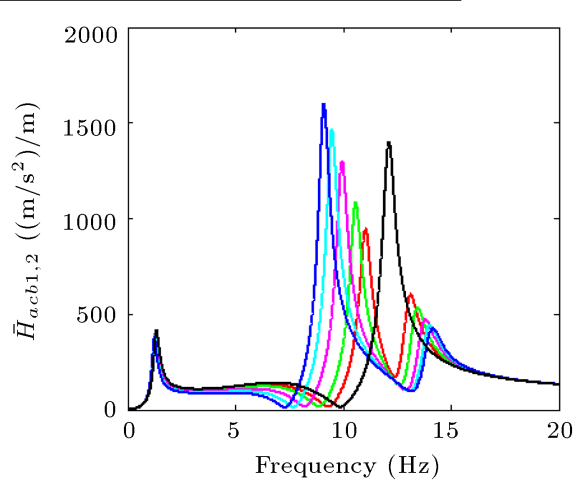

(b)

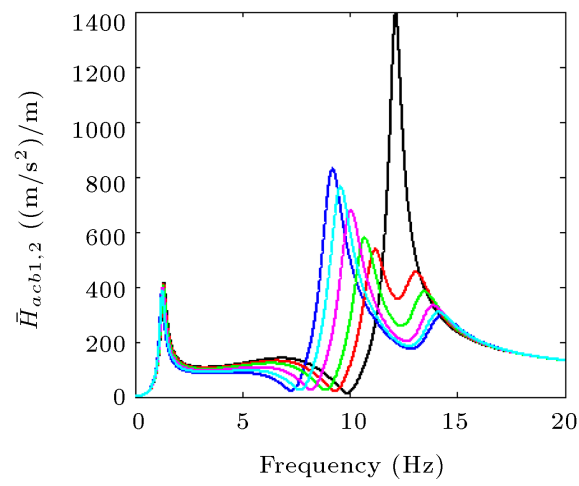

(d)

Figure 5. Response function of car body acceleration; influence of the mass of the equipment: (a) At the car body centre for $\zeta_{e}=0.025$, (b) above the bogies for $\zeta_{e}=0.025$, (c) above the bogies for $\zeta_{e}=0.05$, and (d) above the bogies for $\zeta_{e}=0.075$.

Figure 5 features the acceleration response functions at the car body centre and above bogies for different values of the equipment mass taking into account the eigenfrequency of the equipment $\left(f_{e, o p t}\right)$. It can be noticed that an increase in the equipment mass leads to a larger frequency interval between the low and high values. Another fact is that this increase leads to a reduction in the car body vibrations at the car body centre (Figure 5) at both low and high frequencies. The level of vibrations goes up at a low frequency above 
bogies (Figure 5(b), (c), and (d)) and down at a high frequency for a larger equipment mass. If $\zeta_{e}=0.025$ (Figure $5(\mathrm{~b})$ ), for $m_{e} \geq 3000 \mathrm{~kg}$, the level of vibrations at low frequency is higher than that in the model with no equipment, above the bogies. The level of vibrations above the bogies can be reduced even for large masses of equipment by increasing the damping degree, as shown in Figure 5(c) and (d).

The diagrams in Figure 6 show that mounting position of the equipment has a perceptible impact on the car body bending vibrations obtained for $f_{e, o p t}$. According to some studies in the literature $[2,7,16]$, the level of vibrations due to the car body bending is the lowest when the equipment is fitted at the car body centre. The farther the equipment mounting position gets from the car body centre, the lower the efficiency of reduction in bending vibrations is. Such observations are valid when considering the level of vibrations at low frequency (Figure 6(a)). The equipment has the largest efficiency with $l_{e}=L_{c} / 2$ and goes down to $l_{e}=L_{c} / 3$. Hence, it will no longer have any effects and the level of vibrations is similar to that in the model with no equipment with $l_{e}=L_{c} / 4$. Regarding the level of vibrations at high frequency, the bending vibrations are more efficiently reduced for $l_{e}=L_{c} / 3$ and less for $l_{e}=L_{c} / 2$.

The lowest level of vibrations due to bending is with $l_{e}=L_{c} / 3$ at both low and high frequencies above the bogies (Figure 6(b), (c), and (d)). The level of vibrations will therefore become comparable to that for the model with no equipment if distance $l_{e}$ reaches the value of $L_{c} / 4$.

Figure 7 indicates differences between the results from the model with four pieces of equipment and the model with one piece of equipment for the response functions of car body acceleration calculated by the three models for $f_{e k, o p t}$ and $\zeta_{e}=0.025$. The car body response above the two bogies in the model with four pieces of equipment becomes asymmetrical due to the excitation in the car body pitch. This is not observed in the model with one piece of equipment. We will discuss why ride comfort is different above the two bogies in the following. In addition, there are more peaks corresponding to resonance frequencies on the curve for the response function of car body acceleration in the coupled system with four pieces of equipment. Figure 8 more specifically delineates this. Zero damping in the suspension of both the vehicle and the equipments was

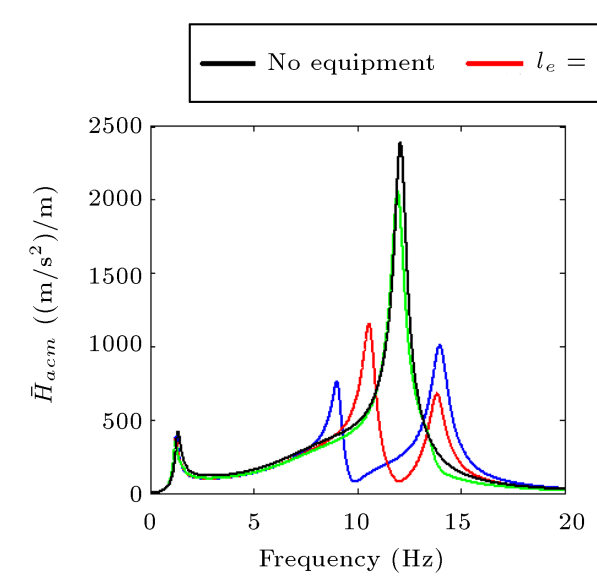

(a)

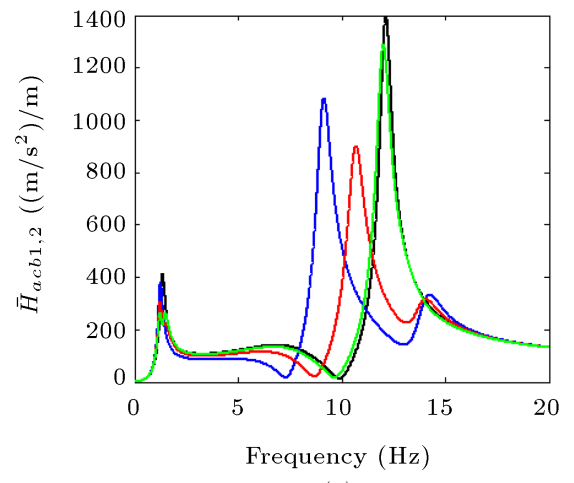

(c)

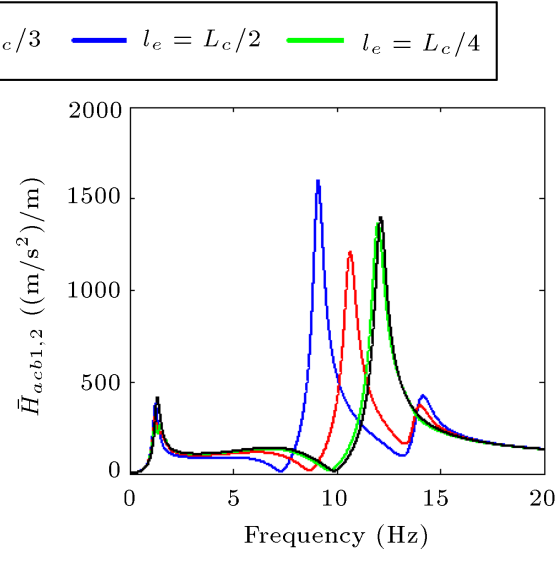

(b)

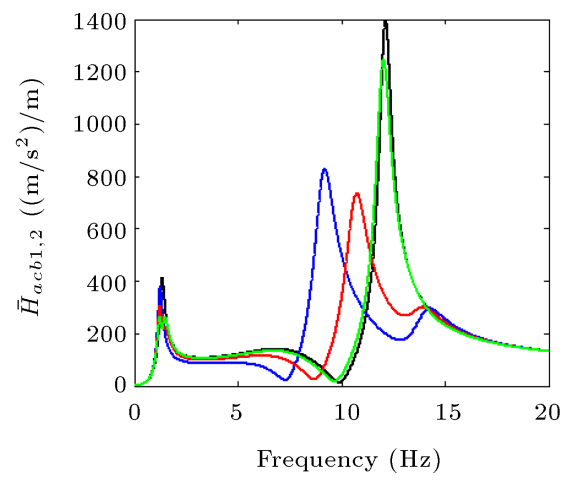

(d)

Figure 6. Response function of car body acceleration; influence of the mounting position of the equipment: (a) At the car body centre for $\zeta_{e}=0.025$, (b) above the bogies for $\zeta_{e}=0.025$, (c) above the bogies for $\zeta_{e}=0.05$, and (d) above the bogies for $\zeta_{e}=0.075$. 


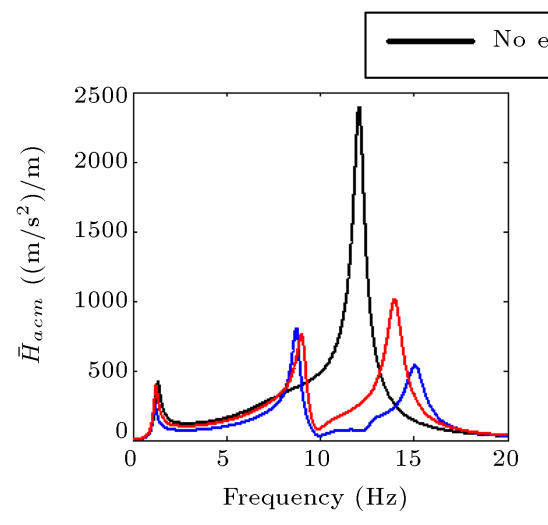

(a)

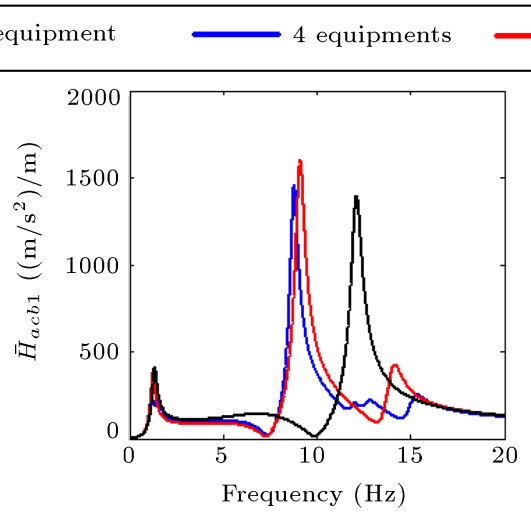

(b)

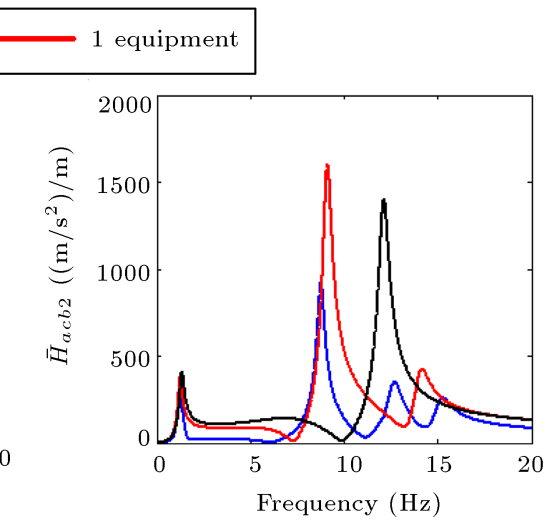

(c)

Figure 7. Response function of car body acceleration: (a) At the car body centre, (b) above the front bogie, and (c) above the rear bogie.

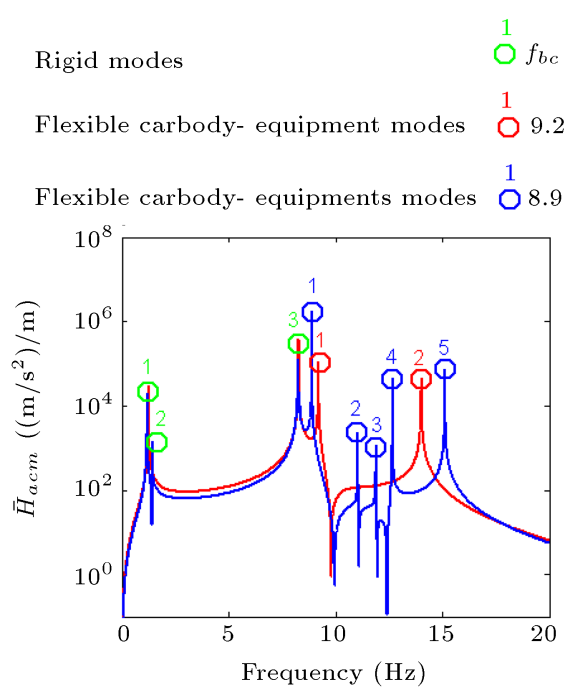

(a) $\stackrel{1}{\bigcirc} f_{b c}=1.25 \mathrm{~Hz} \quad \stackrel{2}{\bigcirc} f_{p c}=1.5 \mathrm{~Hz} \quad \stackrel{3}{\bigcirc} f_{b b}=8.36 \mathrm{~Hz}$

$11 \mathrm{~Hz} \quad \stackrel{2}{\bigcirc} 14 \mathrm{~Hz}$

$8.9 \mathrm{~Hz} \stackrel{2}{\mathrm{O}} 11.05 \mathrm{~Hz} \stackrel{3}{\mathrm{O}} 11.9 \mathrm{~Hz} \stackrel{4}{\mathrm{O}} 12.67 \mathrm{~Hz} \stackrel{5}{\mathrm{O}} 15.12 \mathrm{~Hz}$

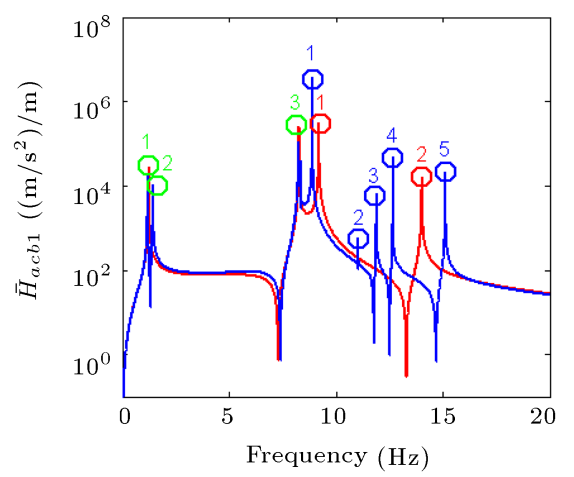

(b)

Figure 8. Response function of car body acceleration for the non-damped case: (a) At the car body centre and (b) above the front bogie.

considered to calculate the response functions of the car body acceleration. There is a peak at the frequency of $1.5 \mathrm{~Hz}$ on the curve of response function at the car body centre (Figure 8(a)) corresponding to the resonance frequency of the car body pitch. This type of vibration occurs at the car body centre as a result of the large asymmetry of the car body due to the existence of the four pieces of equipment with different masses asymmetrically mounted along the car body.

\subsection{Numerical study of the influence of the suspended equipment on vertical ride comfort}

\subsubsection{Ride comfort index}

To evaluate ride comfort, track irregularities are regarded as a stationary stochastic process, which can be described via the power spectral density as in the following equation [19]:

$$
S(\Omega)=\frac{A \Omega_{c}^{2}}{\left(\Omega^{2}+\Omega_{r}^{2}\right)\left(\Omega^{2}+\Omega_{c}^{2}\right)},
$$

where $\Omega$ is the wavelength, $\Omega_{c}=0.8246 \mathrm{rad} / \mathrm{m}, \Omega_{r}=$ $0.0206 \mathrm{rad} / \mathrm{m}$, and $A$ is a coefficient depending on track quality. For a high-level quality track, $A=4.032$. $10^{-7} \mathrm{radm}$, whereas for low-level quality, $A=1.080$. $10^{-6} \mathrm{radm}$.

As a function of the angular frequency $\omega=V \Omega$, the power spectral density of the track irregularities can be written as in the following general relation:

$$
G(\omega)=\frac{S(\omega / V)}{V}
$$

where $V$ is the vehicle velocity. 
Eqs. (28) and (29) will give the power spectral density of the track vertical irregularities in the following form:

$$
G(\omega)=\frac{A \Omega_{c}^{2} V^{3}}{\left[\omega^{2}+\left(V \Omega_{c}\right)^{2}\right]\left[\omega^{2}+\left(V \Omega_{r}\right)^{2}\right]} .
$$

To calculate the power spectral density of car body vertical acceleration, the starting point is in the response function of car body acceleration in Eq. (25) and for the power spectral density of the track irregularities, it is in Eq. (30).

$$
G_{a c}(x, \omega)=G(\omega)\left|\bar{H}_{a c}(x, \omega)\right|^{2} .
$$

It is noteworthy that the calculation of the response function of car body acceleration will depend on the fact that the track vertical irregularities are de-phased against the axles corresponding to the distances between them, i.e. $2 a_{c}$ and $2 a_{b}$. Hence, the functions $\eta_{j}$ describing the track irregularities against the four axles are in the form of:

$$
\begin{aligned}
& \eta_{1,2}(t)=\eta_{0} \cos \omega\left(t+\frac{a_{c} \pm a_{b}}{V}\right), \\
& \eta_{3,4}(t)=\eta_{0} \cos \omega\left(t-\frac{a_{c} \mp a_{b}}{V}\right) .
\end{aligned}
$$

When customizing Eq. (31), the power spectral density of acceleration at the car body centre and above the two bogies will be:

$$
\begin{aligned}
& G_{a c m}(\omega)=G(\omega)\left|\bar{H}_{a c m}(\omega)\right|^{2}, \\
& G_{a c b_{i}}(\omega)=G(\omega)\left|\bar{H}_{a c b_{i}}(\omega)\right|^{2} .
\end{aligned}
$$

To evaluate the comfort in the vertical direction, the partial comfort index is used, which is calculated through relation [20]:

$$
N_{M V}=6 a_{95}^{W_{a b}}
$$

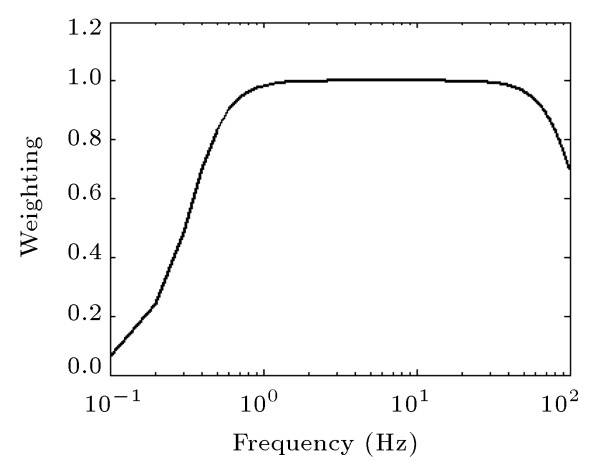

(a) where $a$ is the root mean square of the vertical car body acceleration, 95 refers to the quantile of order $95 \%$, and $W_{a b}=W_{a} \cdot W_{b}$ represents the weight filter of the vertical acceleration [20,21].

The square mean deviation of the vertical acceleration in a random point $x$ of the car body is calculated by using the car body dynamic response, expressed as the acceleration power spectral density, in the equation below:

$$
a=\sqrt{\frac{1}{\pi} \int_{0}^{\infty} G_{a c}(x, \omega) \mathrm{d} \omega} .
$$

Similarly, the square mean deviation of acceleration at the car body centre or above the bogies can be calculated using the relations:

$$
\begin{aligned}
& a_{m}=\sqrt{\frac{1}{\pi} \int_{0}^{\infty} G_{c a m}(\omega) \mathrm{d} \omega,} \\
& a_{b 1,2}=\sqrt{\frac{1}{\pi} \int_{0}^{\infty} G_{a c b 1,2}(\omega) \mathrm{d} \omega .}
\end{aligned}
$$

The filter $W_{a}$ is a passband with the following transfer function (Figure 9(a)):

$$
\begin{aligned}
& H_{a}(s)= \\
& \frac{s^{2}\left(2 \pi f_{2}\right)^{2}}{\left[s^{2}+\frac{2 \pi f_{1}}{Q_{1}} s+\left(2 \pi f_{1}\right)^{2}\right]\left[s^{2}+\frac{2 \pi f_{2}}{Q_{1}} s+\left(2 \pi f_{2}\right)^{2}\right]},
\end{aligned}
$$

with $f_{1}=0.4 \mathrm{~Hz}, f_{2}=100 \mathrm{~Hz}, Q_{1}=0.71$, and $s=i \omega$ (with $i^{2}=-1$ ) [21].

The weighting filter $W_{b}$ takes into account the high human sensitivity to the vertical vibrations and

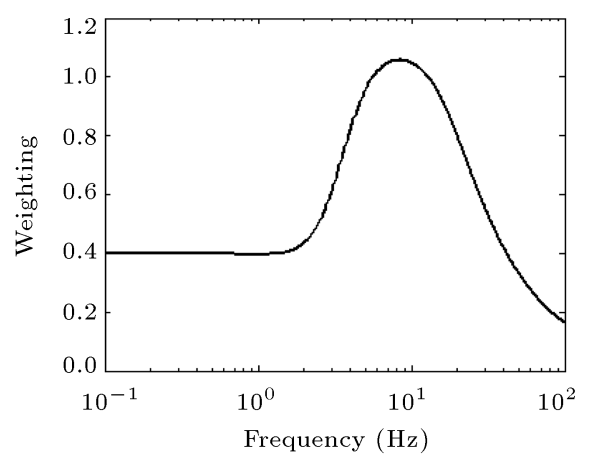

(b)

Figure 9. Transfer functions of the weighting filters: (a) Filter $W_{a}$ and (b) filter $W_{b}$. 
has the transfer function in the form of (Figure $9(\mathrm{~b}))$ :

$$
\begin{aligned}
& H_{b}(s)= \\
& \frac{\left(s+2 \pi f_{3}\right) \cdot\left[s^{2}+\frac{2 \pi f_{5}}{Q_{3}} s+\left(2 \pi f_{5}\right)^{2}\right] 2 \pi K f_{4}^{2} f_{6}^{2}}{\left[s^{2}+\frac{2 \pi f_{4}}{Q_{2}} s+\left(2 \pi f_{4}\right)^{2}\right]\left[s^{2}+\frac{2 \pi f_{6}}{Q_{4}} s+\left(2 \pi f_{6}\right)^{2}\right] f_{3} f_{5}^{2}},
\end{aligned}
$$

where $f_{3}=16 \mathrm{~Hz}, f_{4}=16 \mathrm{~Hz}, f_{5}=2.5 \mathrm{~Hz}, f_{6}=4 \mathrm{~Hz}$, $Q_{2}=0.63, Q_{4}=0.8, K=0.4$, and $s=i \omega$ (with $\left.i^{2}=-1\right)[21]$.

When assuming the hypothesis that the vertical accelerations have a Gaussian distribution with zero mean value, the partial comfort index is:

$$
N_{M V}(x)=6 \Phi^{-1}(0.95) \sqrt{\frac{1}{\pi} \int_{0}^{\infty} G_{a c}(x, \omega)\left|H_{a b}(\omega)\right|^{2} \mathrm{~d} \omega}
$$

where $\Phi^{-1}(0.95)$ represents the quantile of the standard Gaussian distribution with the probability of $95 \%$ and the transfer function $H_{a b}(\omega)=H_{a}(\omega) \cdot H_{b}(\omega)$ (Figure 10).

To calculate the comfort index at the car body centre $\left(N_{M V m}\right)$ and above the two bogies $\left(N_{M V b 1,2}\right)$, the particular relations (33) and (34) for acceleration power spectral density are considered.

\subsubsection{Results of numerical simulations}

This section deals with the influence of the equipment upon ride comfort in correlation with velocity and different values of bending frequency $f_{v b}$ ranging from 7 to $13 \mathrm{~Hz}$. To this end, the ride comfort index will be calculated at the car body centre and above the two bogies based on a model with one piece of equipment and a model with four pieces of equipment. Then, the results will be compared with those for the model with no equipment. This will give a real image of the contribution of the equipment to ride comfort. The possible differences between the results for the two models will be highlighted.

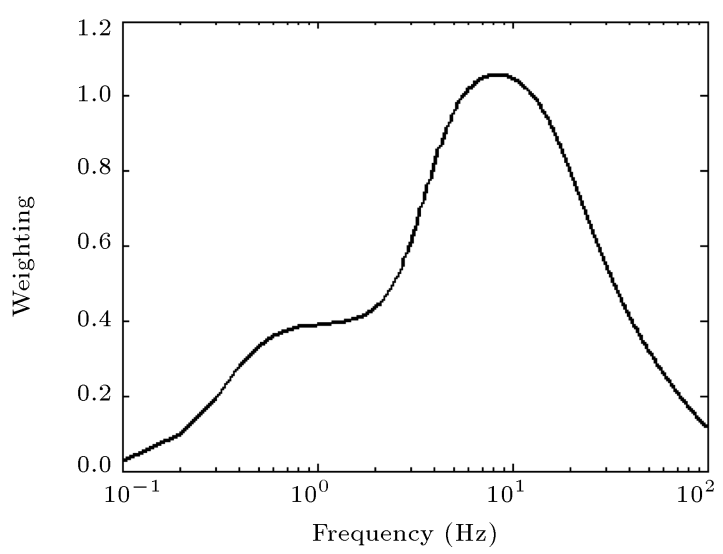

Figure 10. Transfer functions of the filter $W_{a b}$.
The diagrams in Figure 11 show the ride comfort index at the car body centre. A general observation is that the comfort index increases with velocity, irrespective of the model under study. However, this rise is not uniform due to the geometric filtering effect. The geometric filtering effect is an essential feature of the behaviour of vertical vibrations in the railway vehicles and it has extensively been analysed in many papers [22-27]. This effect is mainly due to the manner in which the track excitations are conveyed to the suspended masses via the axles, irrespective of the suspension characteristics. In essence, the geometric filtering effect is the result of the displacement between the vertical movements in the axles due to running on a track with irregularities. This displacement is calculated from the axle position in the assembly of running gear and vehicle velocity. This fact gives the geometric filtering a selective nature, depending on the vehicle wheelbases and velocity of the vehicle car body as well as on a differentiated efficiency in the movement behaviour.

Differences between the comfort index for the model with no equipment and the model with one and four pieces of equipment show an improvement in ride comfort with the use of the equipment. This enhancement varies within a large range, depending on the car body bending frequency $f_{v b}$ and velocity. It is given in Figure 12 through the percentage increase/decrease in ride comfort at the car body centre. A significant rise in ride comfort, which can reach up to 50-60\% at high velocities, requires the car body bending frequency to be lower than $10 \mathrm{~Hz}$. For instance, ride comfort is improved by $65 \%$ for $f_{v b}=8 \mathrm{~Hz}$ at the speed of $255 \mathrm{~km} / \mathrm{h}$ thanks to the presence of the four pieces of equipment. In the simplified model with one piece of equipment, the percentage is $56 \%$.

When the car body bending frequency rises $\left(f_{v b}=\right.$ $12 \mathrm{~Hz}$ or $f_{v b}=13 \mathrm{~Hz}$ ), significant improvement (up to $20-30 \%$ ) in the ride comfort can be seen at velocities smaller than $150 \mathrm{~km} / \mathrm{h}$. For $f_{v b}=12 \mathrm{~Hz}$, at the speed of $125 \mathrm{~km} / \mathrm{h}$, the ride comfort improves by $30 \%$ and $27 \%$ with four pieces and one piece of equipment, respectively. At high velocities, the rise in the ride comfort does not exceed $10 \%$.

The diagrams in Figures 13 and 14 represent the comfort index above the two bogies. Due to different behaviours of vibrations in that position (see Figure 7 ), there are inequalities of the comfort index above the front bogie and the same index above the rear bogie. Nevertheless, a general trend is noticeable in which the comfort index increases with velocity. The rise is not continuous due to the geometric filtering effect and it is higher at the car body centre. The filtering due to the distance between bogies, occurring at the car body centre, does not apply to this case.

Unlike the car body centre where the ride comfort 

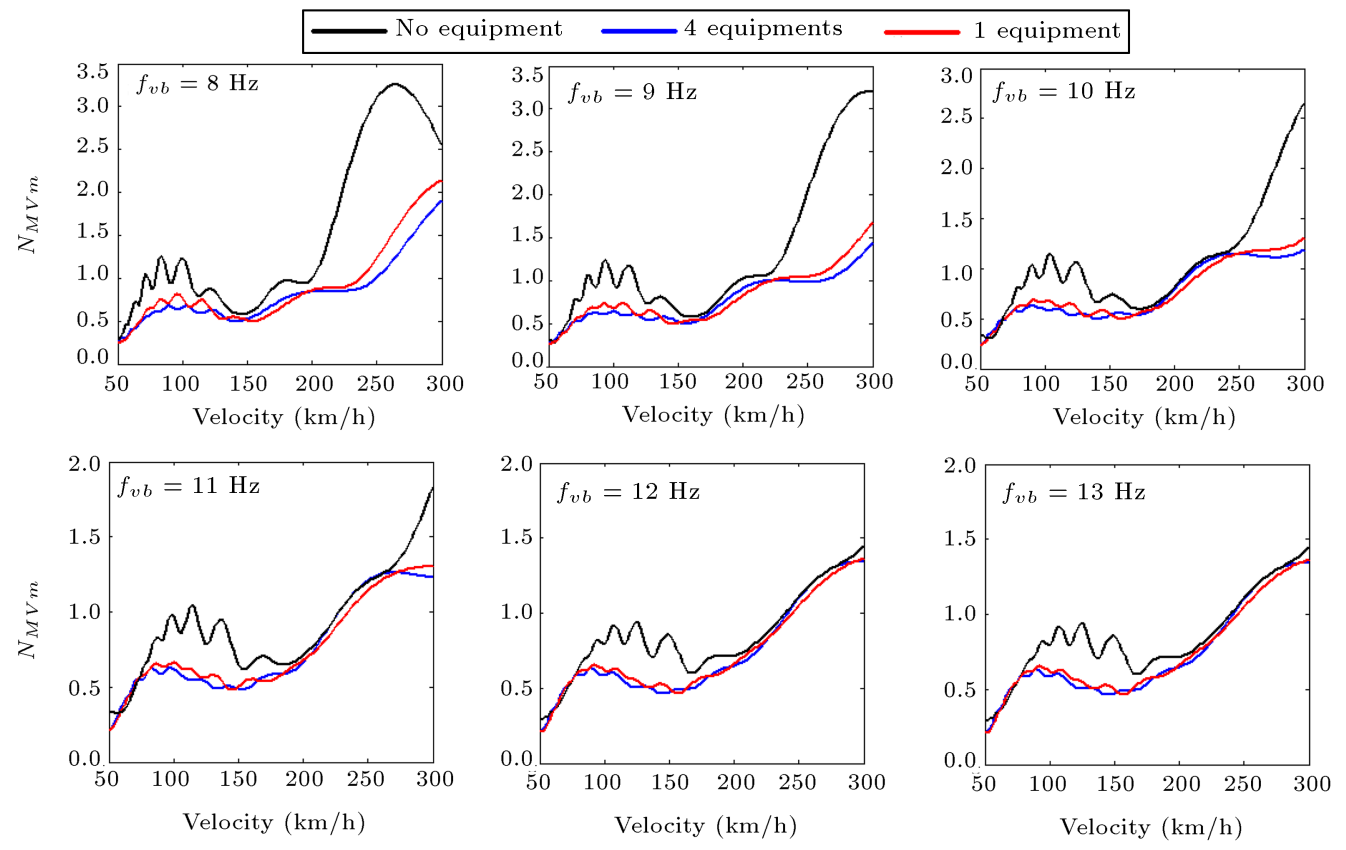

Figure 11. Comfort index at car body centre.

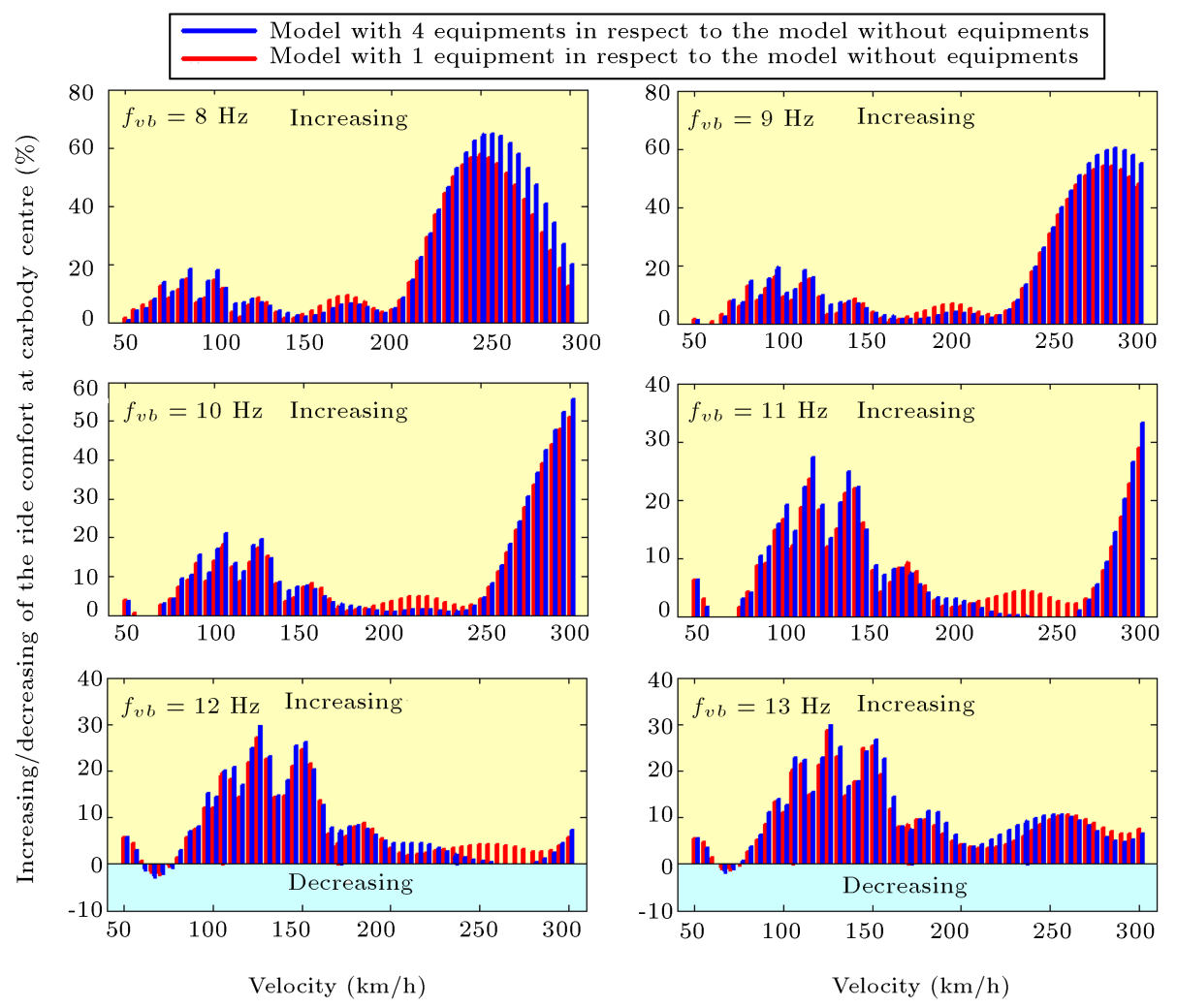

Figure 12. Influence of the equipment upon the ride comfort at the car body centre.

is improved thanks to the equipment, large intervals of speed are noticed above the bogies, where the comfort gets worse. These intervals change depending on the car body bending frequency $f_{v b}$. The increase and the decrease in ride comfort above the bogies, because of the equipment, are shown in Figures 15 and 16.
Considering the comfort index above the front bogie (Figure 15), the most important growth in ride comfort, exceeding $20 \%$, is achieved at velocities higher than $250 \mathrm{~km} / \mathrm{h}$ for $f_{v b}=8 \mathrm{~Hz}$ or $f_{v b}=9 \mathrm{~Hz}$. In practice, the largest increase $(28 \%)$ occurs for the model with four pieces of equipment with $f_{v b}=8 \mathrm{~Hz}$ at 

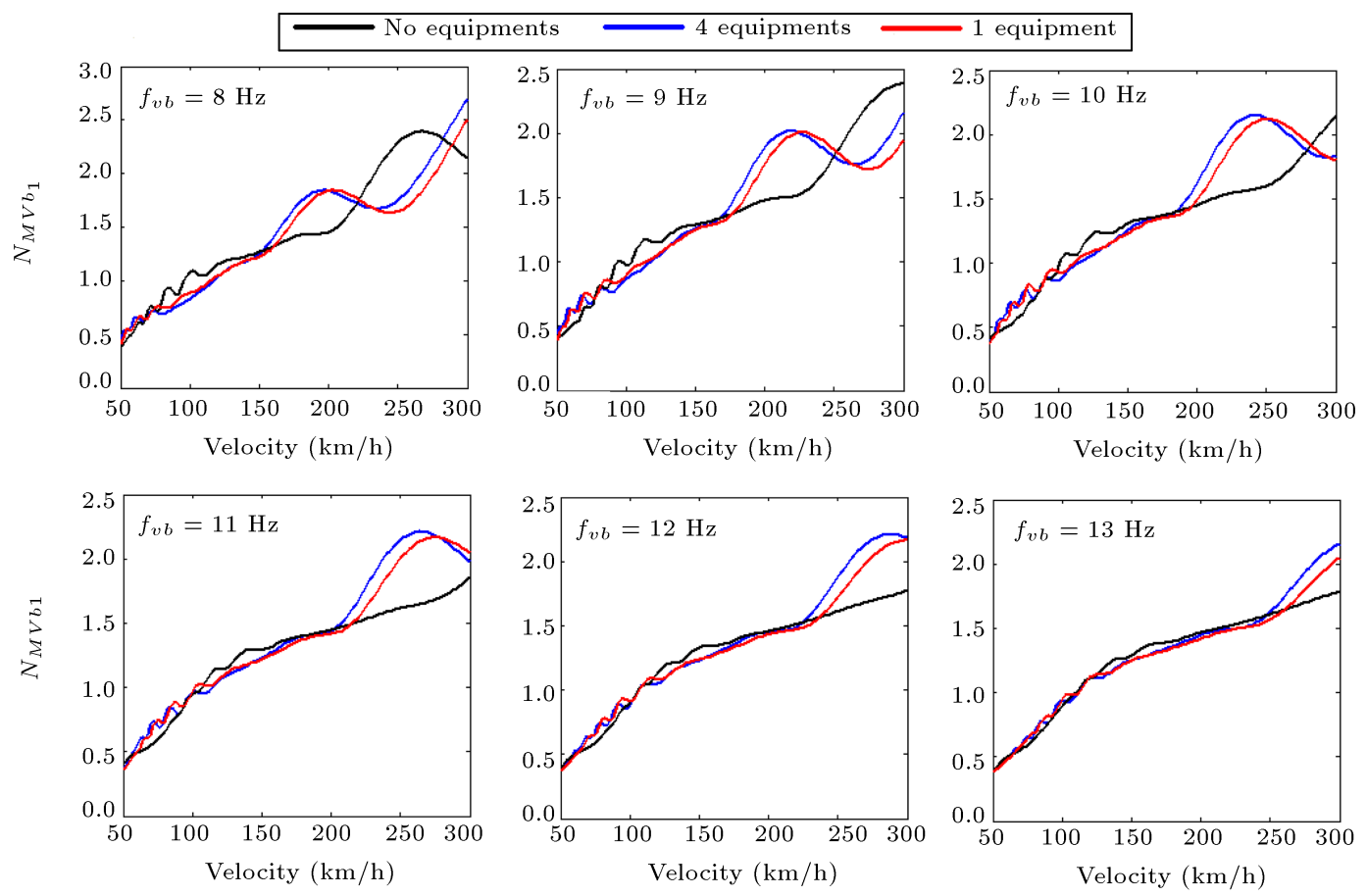

Figure 13. Comfort index above the front bogie.
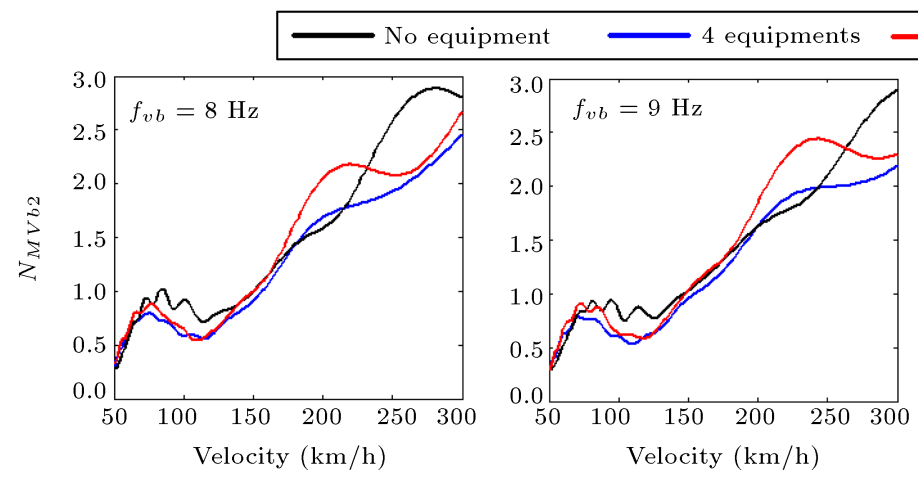

\section{1 equipment}
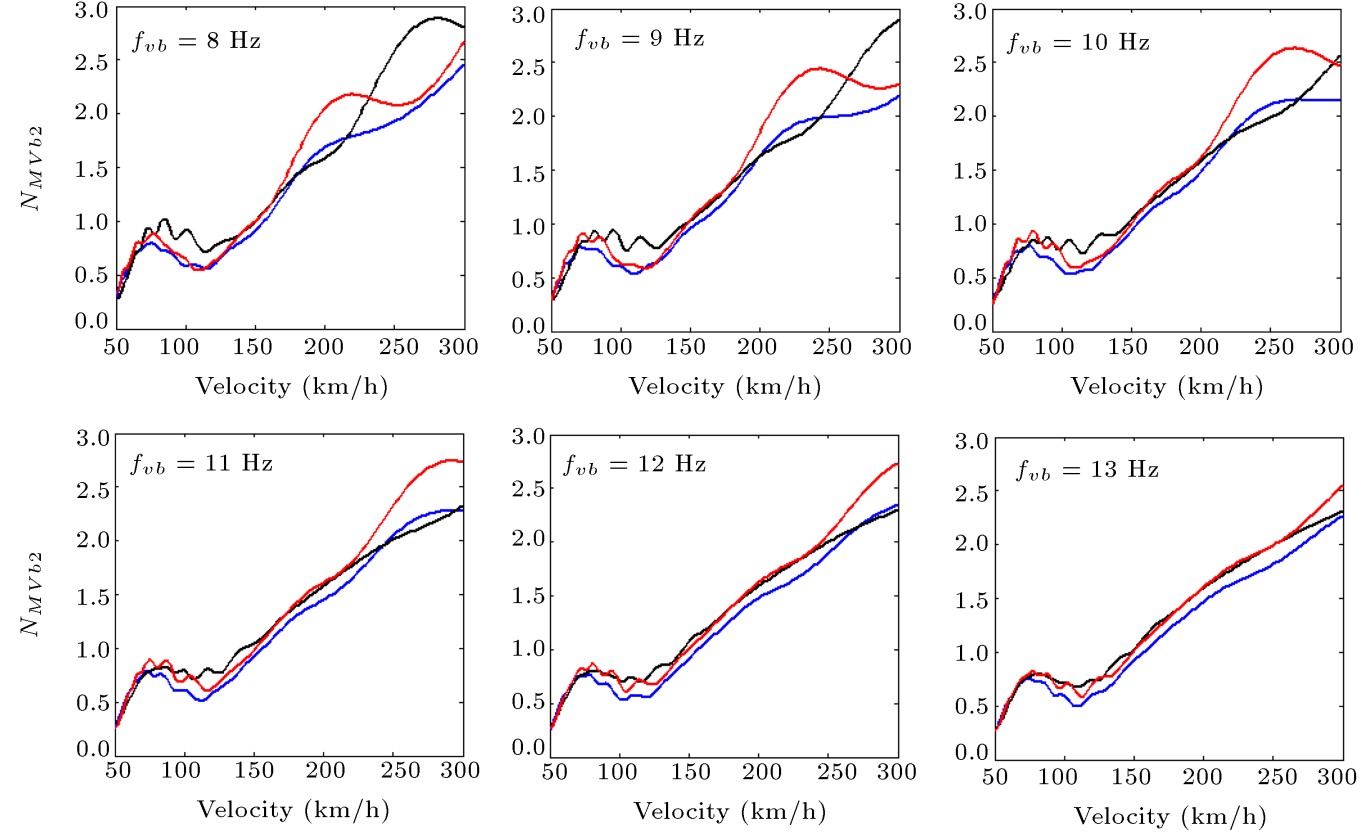

Figure 14. Comfort index above the rear bogie.

$255 \mathrm{~km} / \mathrm{h}$. When $f_{v b}$ goes up, the improvement in ride comfort is reduced to under $7 \%$. As for the decrease in the ride comfort, it is generally maintained under $20 \%$ for $f_{v b}=8 \mathrm{~Hz}$ or $f_{v b}=9 \mathrm{~Hz}$. At higher bending frequencies, the ride comfort will go down by more than $20 \%$, reaching circa $31 \%$ at $260 \mathrm{~km} / \mathrm{h}$ for $f_{v b}=11 \mathrm{~Hz}$ in the model with four pieces of equipment.
There is also a significant enhancement in the ride comfort above the rear bogie (Figure 16) for $f_{v b}<$ $11 \mathrm{~Hz}$. In the model with four pieces of equipment, an increase by circa $26 \%$ in the ride comfort can be noticed for $f_{v b}=8 \mathrm{~Hz}$ at the speed of $265 \mathrm{~km} / \mathrm{h}$. A higher percentage of $30 \%$ is obtained for $f_{v b}=10 \mathrm{~Hz}$ in the model with one piece of equipment at $300 \mathrm{~km} / \mathrm{h}$. 


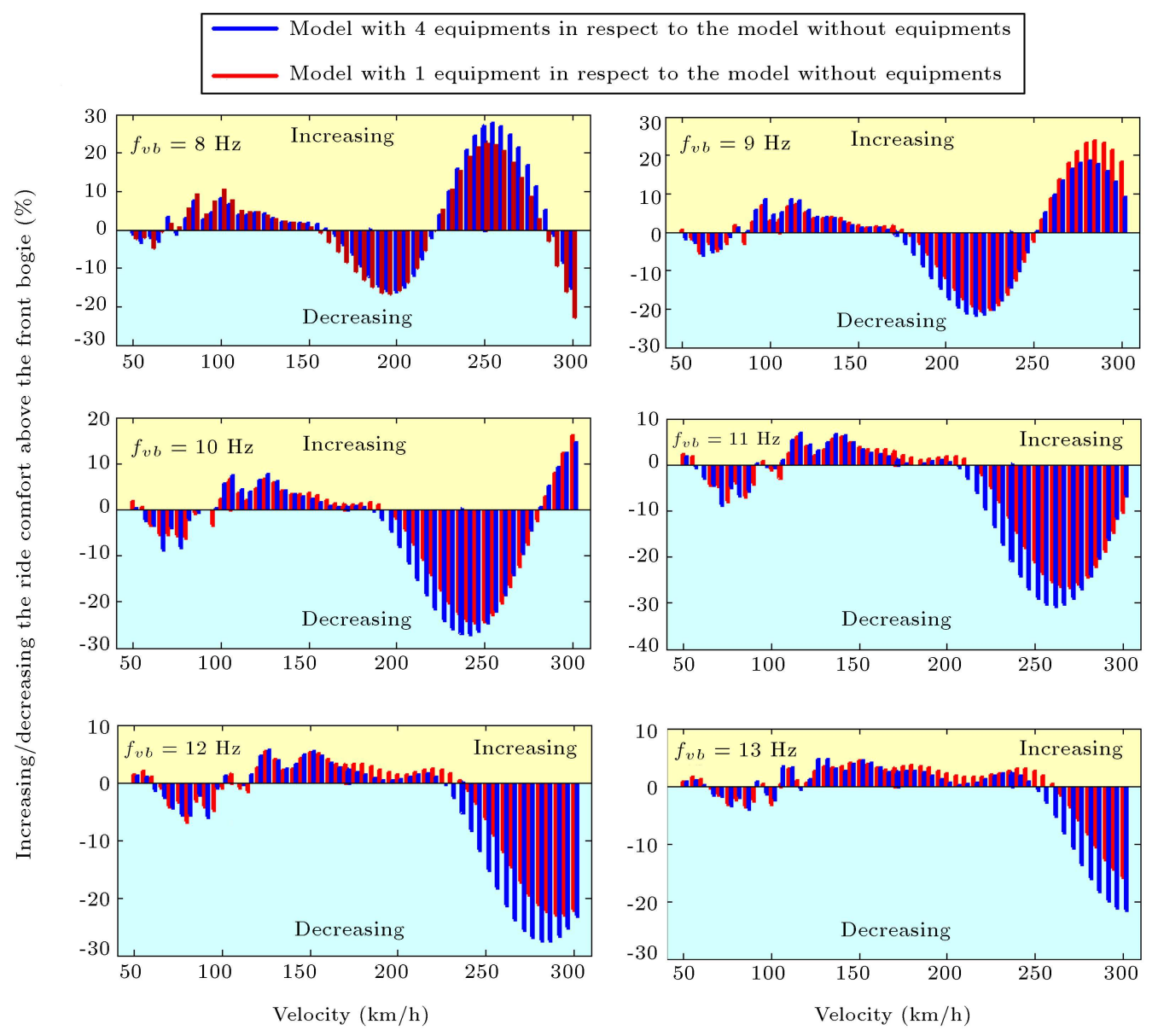

Figure 15. Influence of the equipment on ride comfort above the front bogie.

For higher values of $f_{v b}$, the growth in the ride comfort remains under $10 \%$. The decline in the ride comfort occurs irrespective of the value of the car body bending frequency and it can reach $20 \%$ for $f_{v b}=13 \mathrm{~Hz}$ at $300 \mathrm{~km} / \mathrm{h}$ in the model with one piece of equipment.

It is worth mentioning that the largest reductions in the ride comfort occur in the model with one piece of equipment. For instance, the value of this indicator rises by almost $23 \%$ for $f_{v b}=11 \mathrm{~Hz}$ at $280 \mathrm{~km} / \mathrm{h}$, whereas it is close to $4 \%$ in the model with four pieces of equipment. Moreover, the results for the model with four pieces of equipment show a rise in the ride comfort in some cases, while it goes down in the model with one piece of equipment in the same condition, e.g., $f_{v b}=10 \mathrm{~Hz}$ in the $95-175$ $\mathrm{km} / \mathrm{h}$ speed window. On the other hand, there are circumstances in which the results for the model with four pieces of equipment indicate a decrease in ride comfort while it goes up in the model with one piece of equipment, e.g., $f_{v b}=12 \mathrm{~Hz}$ in the speed range of 90$175 \mathrm{~km} / \mathrm{h}$. Such observations are meant to highlight the differences between the results for the model with four pieces of equipment and the model with one piece of equipment.
From the diagrams in Figures $4-6$, it is evident that the level of vibrations above the bogies at the resonance frequencies can be lowered by increasing the damping degree in the equipment suspension. It is now interesting to see to what extent the ride comfort can be improved above the bogies by raising $\zeta_{e}$ for the speed intervals in which the comfort gets worse due to the equipment. To this purpose, the diagrams in Figure 17 are presented. They show the comfort index above the two bogies for $f_{v b}=11 \mathrm{~Hz}$ (a disadvantageous condition in terms of decrease in ride comfort) calculated for the models with one piece of equipment (Figure 17(a) and (b)) and four pieces of equipment (Figure17(c) and (d)) with the $\zeta_{e}$ values of $0.025,0.05$, and 0.075 .

The increase in the damping ratio of the equipment leads to ride comfort improvement in all the above cases for the entire speed interval. However, the most tangible reduction in the comfort index is at high speeds.

For example, in the model with one piece of equipment, the comfort index lowers by $14.64 \%$ above the front bogie at the speed of $275 \mathrm{~km} / \mathrm{h}$ and by $10.28 \%$ above the rear bogie by the rise of $\zeta_{e}$ from 0.025 to 

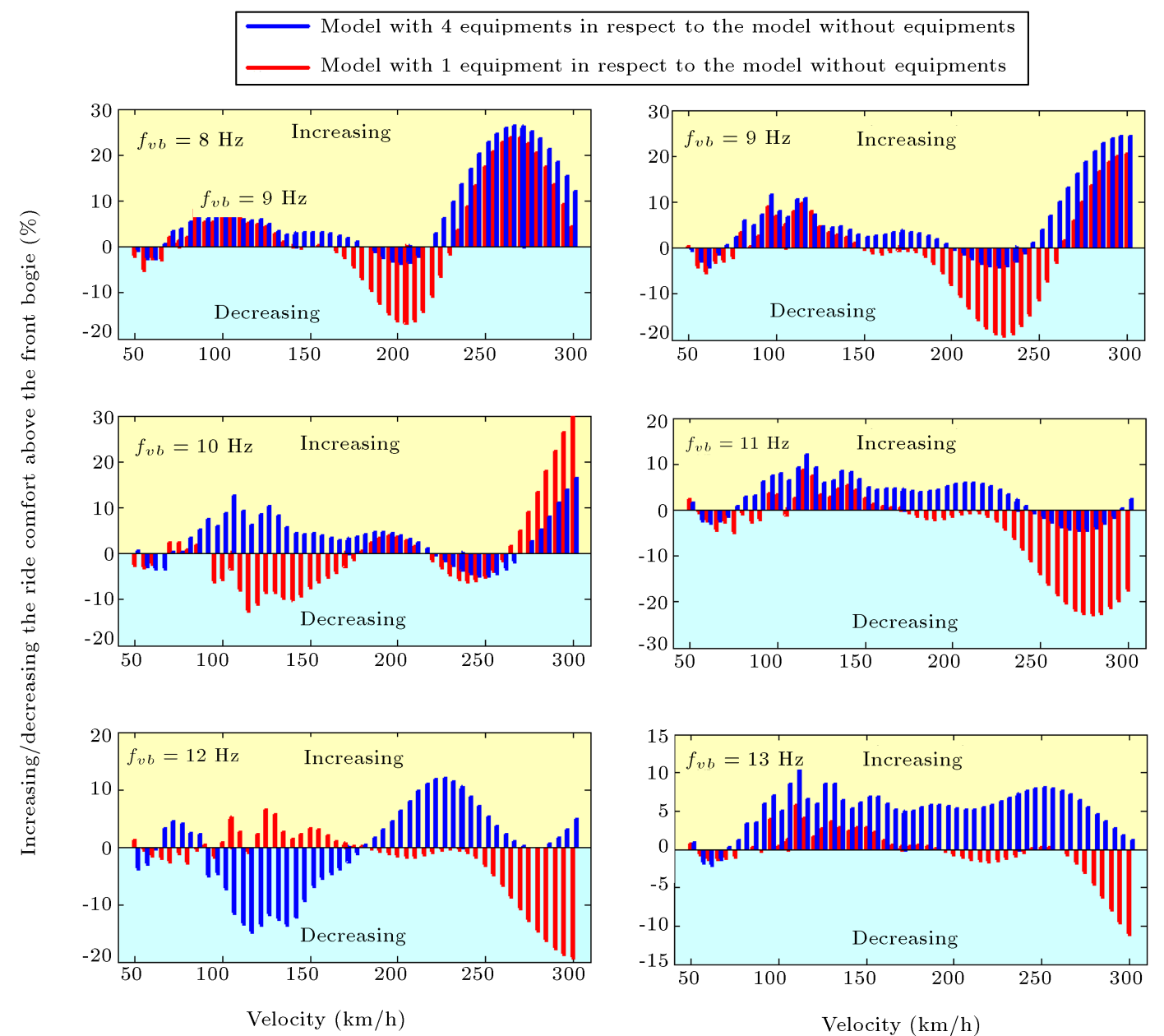

Figure 16. Influence of the equipment on ride comfort above the rear bogie.

0.075. At the same speed, the comfort index will go down by $14.75 \%$ above the front bogie and by $6.27 \%$ above the rear bogie in the model with one piece of equipment when the damping degree goes from 0.025 to 0.075 .

Furthermore, the diagrams in Figure 18 illustrate the differences between the results for the comfort index in the model with one piece of equipment and the model with four pieces of equipment. Such differences change with the speed and $f_{v b}$. The positive values indicate an overestimation of ride comfort (specifically for the model with one equipment) and the negative values imply its underestimation. The largest differences are observable at the car body centre, where they are close to $20 \%$ and generally negative. For $f_{v b}=9 \mathrm{~Hz}$, at $240 \mathrm{~km} / \mathrm{h}$, the difference between the results is $18.8 \%$, whereas it is $18.2 \%$ for $f_{v b}=10 \mathrm{~Hz}$ at the speed of $265 \mathrm{~km} / \mathrm{h}$.

Above the bogies, the differences remain under $16 \%$ with both negative and positive values. Higher values occur above the front bogie for $f_{v b}=8 \mathrm{~Hz}$ and $f_{v b}=9 \mathrm{~Hz}$, indicating underestimation of the ride comfort by $16 \%$ at $275 \mathrm{~km} / \mathrm{h}$ and by $14 \%$ at $300 \mathrm{~km} / \mathrm{h}$, respectively. When $f_{v b}$ rises, the differences between the results for the two models do not exceed $8 \%$.

\section{Conclusions}

This paper investigates the influence of suspended equipment on the car body flexible vibrations and ride comfort in a high-speed vehicle using results from numerical simulations. The vehicle was represented by a rigid-flexible coupled model from which three distinct models were derived, a model with no equipment, a model with one piece of equipment, and a model with four pieces of equipment. Three reference points in the car body were defined at its centre and above the two bogies to obtain the frequency response functions of car body acceleration and the ride comfort index for all the three models.

The goals were, on the one hand, to compare the results for the model with one piece of equipment and the model with four pieces of equipment and, on the other hand, to examine the change in ride comfort exclusively due to the suspended equipment. This was possible by contrasting the results for the model with 


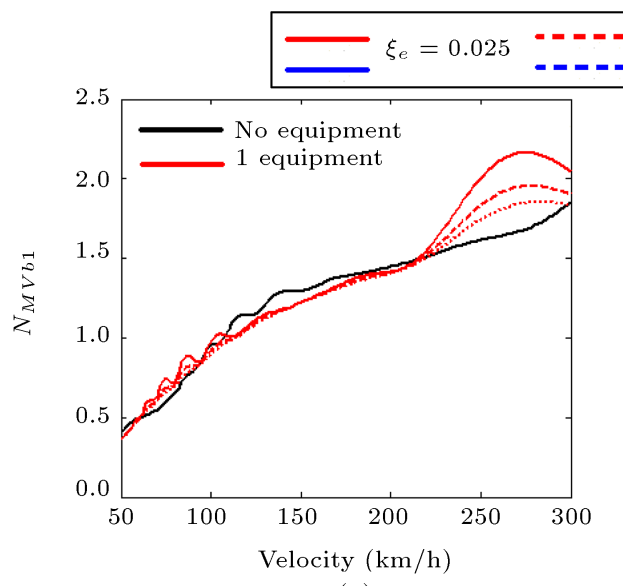

(a)

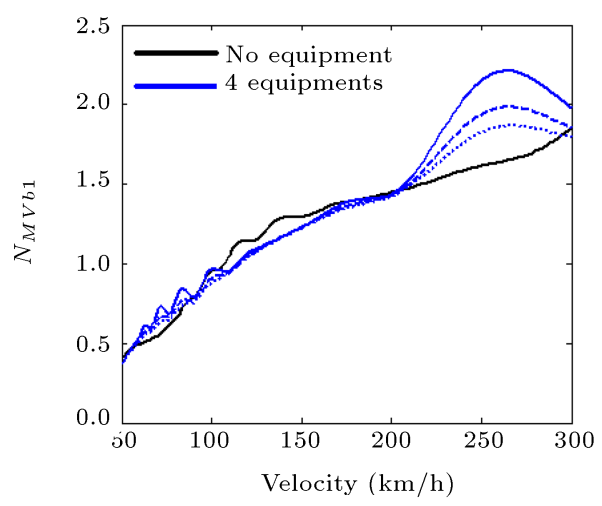

(c)

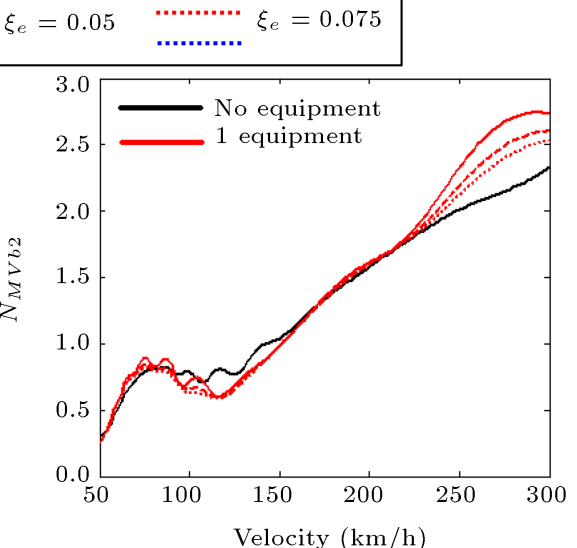

(b)

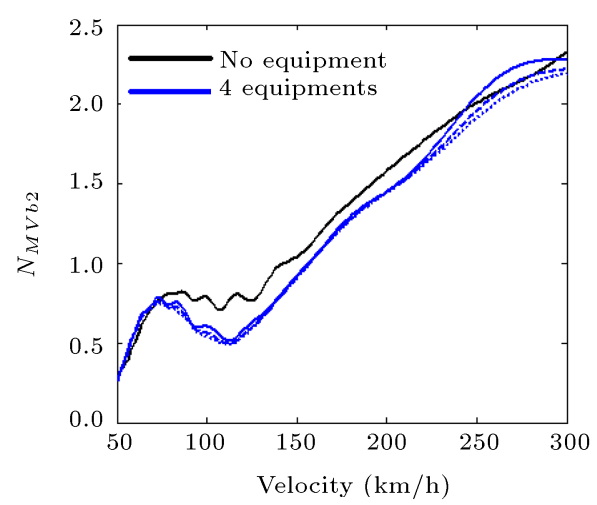

(d)

Figure 17. Influence of the damping degree of the equipment suspension on ride comfort: (a) and (c) above the front bogie, (b) and (d) above the rear bogie.

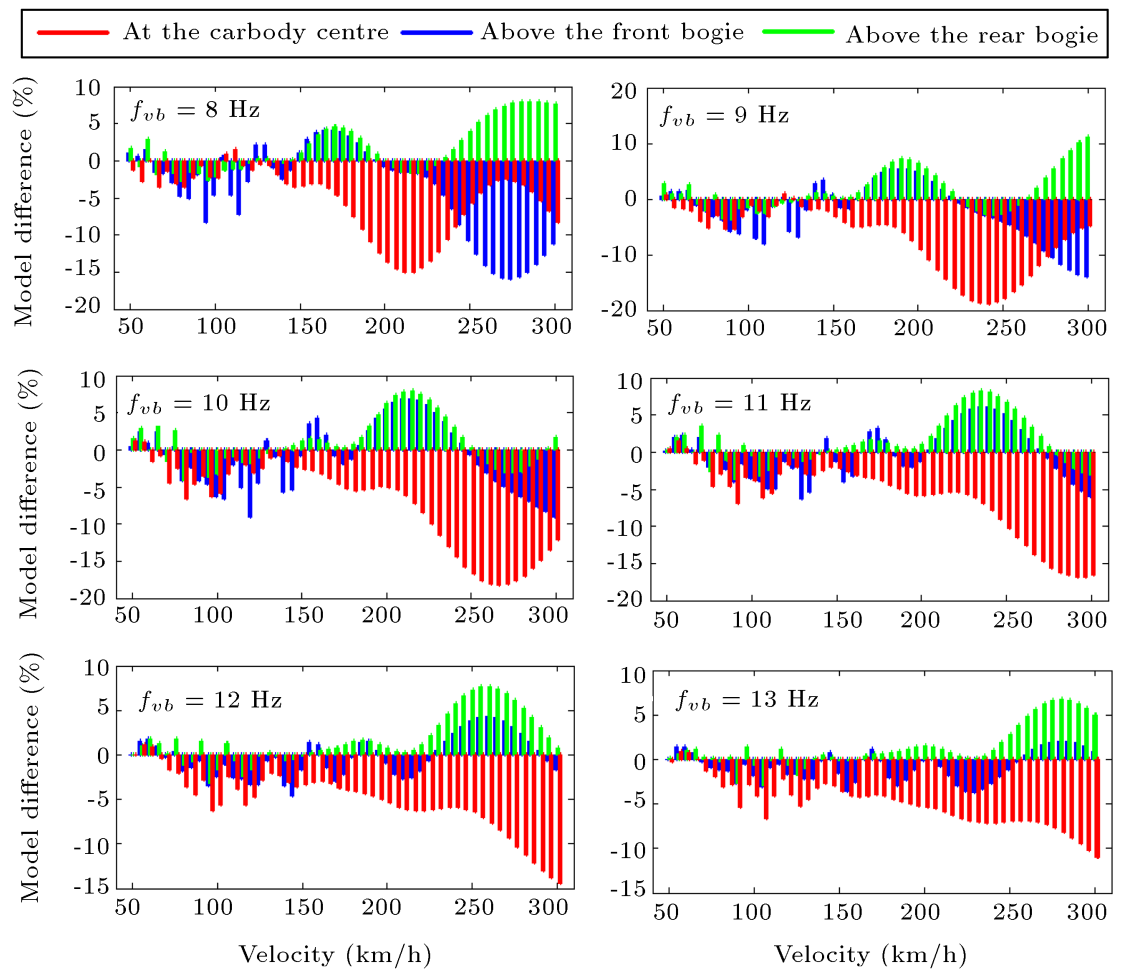

Figure 18. Percentage differences between the results for the models with one and four pieces of equipment. 
one/four piece/s of equipment and the model with no equipment.

The main characteristics of the flexible vibrations of the car body due to the suspended equipment were identified by comparing the results for the frequency response functions of acceleration in the reference points of the car body for the model with one piece of equipment and the model with no equipment. To this purpose, more cases were studied to establish the connection between the suspension manner of the equipment, eigenfrequency of the equipment, the equipment mass, damping degree in the equipment suspension, and its mounting position. Reduction in the bending vibrations at the car body centre was obvious for both the rigidly and the elastically fixed equipment. However, the efficiency of suppressing the bending vibrations was higher in the elastic suspension of the equipment. Above the bogies, the bending vibrations lowered only when the equipment was elastically suspended and the damping degree of the equipment suspension exceeded 0.05 .

In fact, the best results for the reduction in the bending vibrations of the car body in all the three reference points were achieved with high values of damping degree in the equipment suspension. The large mass of the equipment brought about a significant contribution to the decline in the bending vibrations at the car body centre. Above the bogies, the increase in the equipment mass led to higher bending vibrations at the first resonance of the car body-equipment coupled system (relevant from the ride comfort perspective). However, the level of vibrations could decrease for a sufficiently high damping degree in the equipment suspension. Mounting position of the equipment also had a palpable impact on the car body bending vibrations. To have an efficient reduction in the level of vibrations at the first bending resonance frequency in the reference point at the car body centre, it is preferable to have the equipment mounted at the car body centre.

To study the influence of the equipment upon ride comfort in relation to velocity and bending frequency of the car body with no equipment, the ride comfort index was calculated at the car body reference points for the models with one and four pieces of equipment and the results were compared with those for the model with no equipment. Accordingly, an image of the change in ride comfort exclusively due to the equipment was obtained. The differences of the ride comfort index between the models with one piece of equipment and four pieces of equipment were discussed.

It was observed that, generally, the ride comfort index rose with the speed. However, this rise was not uniform due to the geometric filtering effect. In terms of the influence of the equipment upon the ride comfort, the observations were different for each car body reference point. At the centre, the results indicated an improvement in the ride comfort; however, substantial enhancement of up to 50-60\% occurred at high speeds for car body bending frequencies under $10 \mathrm{~Hz}$. Above the bogies, this improvement did not go beyond $30 \%$ at high speeds (due to the presence of equipment), provided that the car body bending frequency was lower than $10 \mathrm{~Hz}$. In addition, ride comfort worsened because of the equipment in large speed intervals. The decline of the ride comfort generally remained under $20 \%$ if the car body bending frequency was smaller than $10 \mathrm{~Hz}$, but it could reach circa $30 \%$ at higher car body bending frequencies.

Based on the comparison of the results for the model with four pieces of equipment and the model with one piece of equipment:

1. At the car body centre, the ride comfort was overestimated for the model with one piece of equipment. The overestimation was close to $20 \%$ at high speeds and bending frequencies under $10 \mathrm{~Hz}$;

2. Above the bogies, the ride comfort index in the model with one piece of equipment was overestimated/underestimated. The same held for the model with four pieces of equipment by up to $16 \%$.

\section{References}

1. Tomioka, T., Takigami, T., and Suzuki, Y. "Numerical analysis of three-dimensional flexural vibration of railway vehicle car body", Veh. Syst. Dyn., 44, pp. 272-285 (2006).

2. Huang, C., Zeng, J., Luo, G., and Shi, H. "Numerical and experimental studies on the car body flexible vibration reduction due to the effect of car bodymounted equipment", Proc IMechE Part F: J Rail and Rapid Transit, 232(1), pp. 103-120 (2018).

3. Sun, W., Zhou, J., Gong, D., and You, T. "Analysis of modal frequency optimization of railway vehicle car body", Advances in Mechanical Engineering, 8(4), pp. 1-12 (2016).

4. Yang, G., Wang, C., Xiang, F., and Xiao, S. "Effect of train carbody's parameters on vertical bending stiffness performance", Chinese Journal of Mechanical Engineering, 29(6), pp. 1120-1126 (2016).

5. Diana, G., Cheli, F., Collina, A., et al. "The development of a numerical model for railway vehicles comfort assessment through comparison with experimental measurements", Veh. Syst. Dyn., 38(3), pp. 165-183 (2002).

6. Ye, H., Zeng, J., Wang, Q., and Han, X. "Study on carbody flexible vibration considering layout of underneath equipment and doors", 4th International Conference on Sensors, Measurement and Intelligent Materials (ICSMIM 2015), Shenzhen, China, pp. 1177-1183 (2015).

7. Shi, H.L., Luo, R., Wu, P.B., et al. "Application of DVA theory in vibration reduction of carbody with 
suspended equipment for high-speed EMU", Science China Technological Sciences, 57(7), pp. 1425-1438 (2014).

8. Luo, G., Zeng, J., and Wang, Q. "Identifying the relationship between suspension parameters of underframe equipment and carbody modal frequency", Journal Modern Transport, 22(4), pp. 206-213 (2014).

9. Dumitriu, M. "Influence of suspended equipment on the carbody vertical vibration behaviour of high-speed railway vehicles", Archive of Mechanical Engineering, 63(1), pp. 25-44 (2016).

10. Wu, H.C., Wu, P.B., Zeng, J., et al. "Influence of equipment under car on carbody vibration", J. Traffic Trans. Eng., 12(5), pp. 50-56 (2012).

11. Shi, H.L., Wu, P.B., and Luo, R. "Coupled vibration characteristics of flexible car body and equipment of EMU", J Southwest Jiaotong Univ, 49(4), pp. 693-699 (2014).

12. Sun, Y., Gong, D., and Zhou, J. "Study on vibration reduction design of suspended equipment of high speed railway vehicles", Journal of Physics: Conference Series, 744, Paper no. 012212 (2016).

13. Aida, K.Y., Tomioka, T., Takigami, T., et al. "Reduction of carbody flexural vibration by the high-damping elastic support of under-floor equipment", Quarterly Report of RTRI, 56(4), pp. 262-267 (2015).

14. Shi, H., Luo, R., Wu, P., et al. "Influence of equipment excitation on flexible carbody vibration of EMU", Journal Modern Transport, 22(4), pp. 195-205 (2014).

15. Shi, H.L., Luo, R., Wu, P.B., and Zeng, J. "Suspension parameters designing of equipment for electric multiple units based on dynamic vibration absorber theory", $J$ Mech Eng, 50(14), pp. 155-161 (2014).

16. Sun, W., Gong, D., Zhou, J., and Zhao, Y. "Influences of suspended equipment under car body on highspeed train ride quality", Procedia Engineering, 16, pp. 812 -817 (2011).

17. Nie, Y.Z., Zeng, J., and Li. F.G. "Research on resonance vibration simulation method of high-speed railway vehicle carbody", International Industrial Informatics and Computer Engineering Conference (IIICEC 2015), Xi'an, Shaanxi, China, pp. 1117-1121 (2015).

18. Shi, H. and Wu, P. "Flexible vibration analysis for car body of high-speed EMU", J. Mech. Sci. Technol., 30(1), pp. 55-66 (2016).
19. C 116, "Interaction between vehicles and track. RP 1, Power spectral density of track irregularities, Part 1: Definitions, conventions and available data", Utrecht (1971).

20. ENV 12299 "Railway applications ride comfort for passengers measurement and evaluation" (1997).

21. UIC 513 R Guidelines for Evaluating Passenger Comfort in Relation to Vibration in Railway Vehicle, International Union of Railways (1994).

22. Zhou, J., Goodall, R., Ren, L., and Zhang, H. "Influences of car body vertical flexibility on ride quality of passenger railway vehicles", Proc IMechE Part F:J Rail and Rapid Transit, 223, pp. 461-471 (2009).

23. Zhou, J. and Wenjing, S. "Analysis on geometric filtering phenomenon and flexible car body resonant vibration of railway vehicles", Journal of Tongji University, 37(12), pp. 1653-1657 (2009).

24. Gong, D., Zhou, J., and Sun, W.J. "On the resonant vibration of a flexible railway car body and its suppression with a dynamic vibration absorber", Journal of Vibration and Control, 19(5), pp. 649-657 (2013).

25. Gong, D., Jia, Y., Song, G., and Zhou, J. "Study on geometry filtering phenomenon and flexible car body resonant vibration of articulated trains", Advanced Materials Research, 787, pp. 542-547 (2013).

26. Dumitriu, M. "Analysis of the dynamic response in the railway vehicles to the track vertical irregularities. Part I: The theoretical model and the vehicle response functions", Journal of Engineering Science and Technology Review, 8(4), pp. 24-31 (2015).

27. Dumitriu, M. "Analysis of the dynamic response in the railway vehicles to the track vertical irregularities. Part II: The numerical analysis", Journal of Engineering Science and Technology Review, 8(4), pp. 32-39 (2015).

\section{Biography}

Mădălina Dumitriu is an Associate Professor in the Department of Railway Vehicles, Faculty of Transportation, University Polytehnica of Bucharest, Romania. Her main area of research is railway vehicle dynamics, including the topics related to the vibration behaviour of the railway vehicles and ride comfort. She has published 7 books and more than 100 papers in reputable journals and international conference proceedings. 